\title{
The complete mitogenome of Arion vulgaris Moquin-Tandon, 1855 (Gastropoda: Stylommatophora): Mitochondrial genome architecture, evolution and phylogenetic considerations within Stylommatophora
}

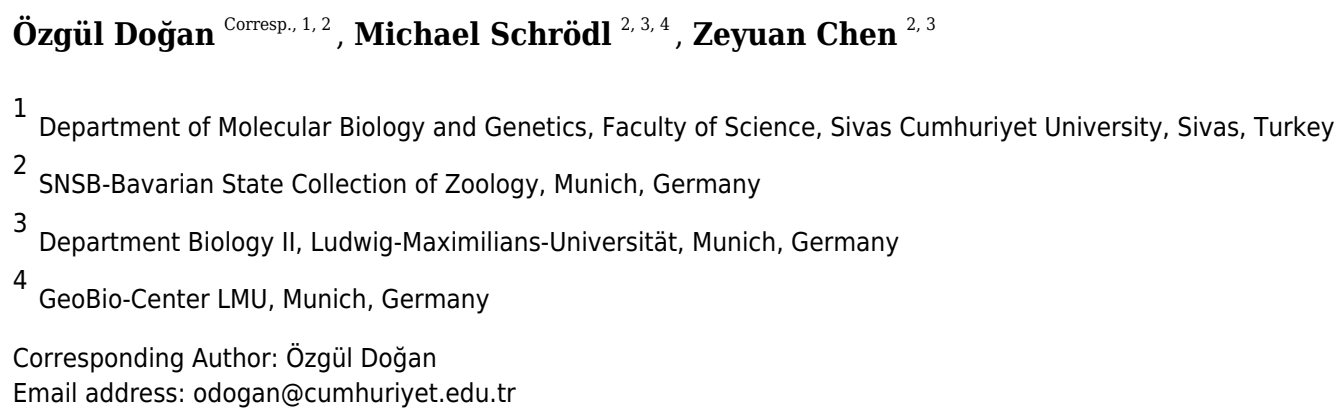

Stylommatophora is one of the most speciose orders of Gastropoda, including terrestrial snails and slugs, some of which are economically important as human food, agricultural pests, vectors of parasites or due to invasiveness. Despite their great diversity and relevance, the internal phylogeny of Stylommatophora has been debated. To date, only 34 stylommatophoran mitogenomes were sequenced. Here, the complete mitogenome of an invasive pest slug, Arion vulgaris Moquin-Tandon, 1855 (Stylommatophora: Arionidae), was sequenced using next generation sequencing, analysed and compared with other stylommatophorans. The mitogenome of $A$. vulgaris measures $14,547 \mathrm{bp}$ and contains 13 protein-coding, two rRNA, 22 tRNA genes, and one control region, with an A + T content of $70.20 \%$. All protein coding genes (PCGs) are initiated with ATN codons except for COX1, ND5 and ATP8 and all are ended with TAR or T- stop codons. All tRNAs were folded into a clover-leaf secondary structure except for trnC and trnSI (AGN). Phylogenetic analyses confirmed the position of $A$. vulgaris within the superfamily Arionoidea, recovered a sister group relationship between Arionoidea and Orthalicoidea, and supported monophyly of all currently recognized superfamilies within Stylommatophora. Initial diversification time of the Stylommatophora was estimated as 138.55 million years ago corresponding to Early Cretaceous. The divergence time of $A$. vulgaris and Arion rufus (Linnaeus, 1758) was estimated as 15.24 million years ago corresponding to one of Earth's most recent, global warming events, the Mid-Miocene Climatic Optimum. Furthermore, selection analyses were performed to investigate the role of different selective forces shaping stylommatophoran mitogenomes. Although purifying selection is the predominant selective force shaping stylommatophoran mitogenomes, six genes (ATP8, COX1, COX3, ND3, ND4 and ND6) 
detected by the branch-specific aBSREL approach and three genes (ATP8, CYTB and ND4L) detected by codon-based BEB, FUBAR and MEME approaches were exposed to diversifying selection. The positively selected substitutions at the mitochondrial PCGs of stylommatophoran species seems to be adaptive to environmental conditions and affecting mitochondrial ATP production or protection from reactive oxygen species effects. Comparative analysis of stylommatophoran mitogenome rearrangements using MLGO revealed conservatism in Stylommatophora; exceptions refer to potential apomorphies for several clades including rearranged orders of trnW-trnY and of trnE-trnQ-rrnS-trnM-trnL2ATP8-trnN-ATP6-trnR clusters for the genus Arion. Generally, tRNA genes tend to be rearranged and tandem duplication random loss, transitions and inversions are the most basic mechanisms shaping stylommatophoran mitogenomes. 
1 The complete mitogenome of Arion vulgaris Moquin-Tandon, 1855 (Gastropoda:

2 Stylommatophora): Mitochondrial genome architecture, evolution and phylogenetic

3 considerations within Stylommatophora

4

5 Özgül Doğan ${ }^{1,2^{*}}$, Michael Schrödl ${ }^{2,3,4}$, Zeyuan Chen ${ }^{2,3}$

6

$7{ }^{1}$ Department of Molecular Biology and Genetics, Faculty of Science, Sivas Cumhuriyet

8 University, 58140 Sivas, Turkey.

$9 \quad 2$ SNSB-Bavarian State Collection of Zoology, 81247 Munich, Germany.

$10{ }^{3}$ Department Biology II, Ludwig-Maximilians-Universität, 82152 Planegg-Martinsried, Munich,

11 Germany.

$12{ }^{4}$ GeoBio-Center LMU, 80333 Munich, Germany.

$16{ }^{*}$ Corresponding Author:

17 Özgül Doğan ${ }^{1,2}$

18 Department of Molecular Biology and Genetics, Faculty of Science, Sivas Cumhuriyet

19 University, 58140 Sivas, Turkey.

20 Email address: odogan@cumhuriyet.edu.tr 


\section{ABSTRACT}

22 Stylommatophora is one of the most speciose orders of Gastropoda, including terrestrial snails

23 and slugs, some of which are economically important as human food, agricultural pests, vectors

24 of parasites or due to invasiveness. Despite their great diversity and relevance, the internal

25 phylogeny of Stylommatophora has been debated. To date, only 34 stylommatophoran

26 mitogenomes were sequenced. Here, the complete mitogenome of an invasive pest slug, Arion

27 vulgaris Moquin-Tandon, 1855 (Stylommatophora: Arionidae), was sequenced using next

28 generation sequencing, analysed and compared with other stylommatophorans. The mitogenome

29 of A vulgaris measures $14,547 \mathrm{bp}$ and contains 13 protein-coding, two rRNA, 22 tRNA genes,

30 and one control region, with an A + T content of $70.20 \%$. All protein coding genes (PCGs) are

31 initiated with ATN codons except for COX1, ND5 and ATP8 and all are ended with TAR or T-

32 stop codons. All tRNAs were folded into a clover-leaf secondary structure except for trnC and

33 trnS1 (AGN). Phylogenetic analyses confirmed the position of $A$. vulgaris within the

34 superfamily Arionoidea, recovered a sister group relationship between Arionoidea and

35 Orthalicoidea, and supported monophyly of all currently recognized superfamilies within

36 Stylommatophora. Initial diversification time of the Stylommatophora was estimated as 138.55

37 million years ago corresponding to Early Cretaceous. The divergence time of $A$. vulgaris and

38 Arion rufus (Linnaeus, 1758) was estimated as 15.24 million years ago corresponding to one of

39 Earth's most recent, global warming events, the Mid-Miocene Climatic Optimum. Furthermore,

40 selection analyses were performed to investigate the role of different selective forces shaping

41 stylommatophoran mitogenomes. Although purifying selection is the predominant selective force

42 shaping stylommatophoran mitogenomes, six genes (ATP8, COX1, COX3, ND3, ND4 and ND6)

43 detected by the branch-specific aBSREL approach and three genes (ATP8, CYTB and ND4L)

44 detected by codon-based BEB, FUBAR and MEME approaches were exposed to diversifying 
45 selection. The positively selected substitutions at the mitochondrial PCGs of stylommatophoran

46 species seems to be adaptive to environmental conditions and affecting mitochondrial ATP

47 production or protection from reactive oxygen species effects. Comparative analysis of

48 stylommatophoran mitogenome rearrangements using MLGO revealed conservatism in

49 Stylommatophora; exceptions refer to potential apomorphies for several clades including

50 rearranged orders of trn $W$-trn $Y$ and of $\operatorname{trnE}$-trnQ-rrnS-trnM-trnL2-ATP8-trnN-ATP6-trnR

51 clusters for the genus Arion. Generally, tRNA genes tend to be rearranged and tandem

52 duplication random loss, transitions and inversions are the most basic mechanisms shaping

53 stylommatophoran mitogenomes. 


\section{INTRODUCTION}

56 Gastropoda is the most speciose class of Mollusca, including snails and slugs with very diverse

57 feeding habits and a wide range of habitats (Barker, 2009). The about 63,000 gastropod species

58 represent 476 families (Bouchet et al., 2017) and radiated in marine, freshwater and terrestrial

59 ecosystems with detritivorous, herbivorous, carnivorous, predatory or parasitic life styles

60 (Ponder \& Lindberg, 1997). Most of the terrestrial gastropods are stylommatophoran

61 pulmonates, with approximately 30,000 species distributed from polar to tropical regions

62 (Mordan \& Wade, 2008). Stylommatophorans are economically important as human food and

63 because of their status of being major agricultural pests and/or vectors of parasites and

64 invasiveness (Barker, 2009). The origin of Stylommatophora is within panpulmonate

65 heterobranchs (Jörger et al., 2010) and the monophyly of the order is undisputed. Internal

66 phylogenetic relationships of stylommatophorans were poorly resolved based on morphology but

67 then investigated molecularly in different sampling sets of taxa with various methods and

68 basically relatively short sequences. Tillier, Masselmot \& Tillirt, (1996) used the D2 region of

$6928 S$ rRNA to explore the phylogenetic relationships of pulmonates including a few

70 stylommatophoran species, however they reported that these short sequences would not have

71 sufficient resolving power for investigating the relationships owing to the probable rapid

72 radiation of pulmonate species. Wade, Mordan \& Clarke, (2001) and Wade, Mordan \& Naggs,

73 (2006) presented more comprehensive molecular phylogenies based on relatively longer

74 sequence information of the rRNA gene-cluster using 104 species (Wade, Mordan \& Clarke,

75 2001) and 160 species (Wade, Mordan \& Naggs, 2006) from Stylommatophora. Although these

76 phylogenetic reconstructions accurately supported the monophyly of achatinoid and non-

77 achatinoid clades, some clades of families that traditionally have been assumed to be 
78 monophyletic and some of the morphological groups based on excretory system, in particular

79 monophyly of some families and morphological groups were not supported.

80 The emergence and divergence time of Stylommatophora is also doubtful due to the fragmentary

81 fossil records. The earliest land snails identified as stylommatophoran species are from upper

82 Carboniferous and Permian but their classification has still been controversial (Solem \&

83 Yochelson, 1979; Hausdorf, 2000). Bandel, (1991) and Roth et al., (1996) suggested the oldest

84 known fossil records from late Jurassic and Early Cretaceous (Cheruscicola) and Early

85 Cretaceous (Pupilloidea). Tillier, Masselmot \& Tillirt, (1996) inferred that the Stylommatophora

86 emerged in the transition between late Cretaceous and Paleocene (65-55 Ma) congruent with

87 fossil records, based on the molecular data. However, all of the previous molecular dating

88 analyses on Stylommatophora have been performed either with limited numbers of taxa or

89 molecular markers (Tillier, Masselmot \& Tillirt, 1996; Jörger et al., 2010; Dinapoli \&

90 Klussmann-Kolb, 2010; Zapata et al., 2014), therefore there is a need for further investigations in

91 a more comprehensive sampling using more markers for better understanding of the phylogeny

92 and timing of evolution of Stylommatophora.

93 In recent years, there is a rapid increase in the number of sequenced mitochondrial genomes

94 (mitogenomes) in parallel to revolution on high throughput DNA sequencing technology and

95 data mining, providing a powerful tool for phylogenetic analysis (Moritz, Dowling \& Brown,

96 1987; Boore, 1999; Bernt et al., 2013a). Animal mitogenomes are double-stranded circular

97 molecules which are $\sim 16 \mathrm{~kb}$ in length and contain 13 protein coding genes (PCGs) forming the

98 respiratory chain complexes: Complex I or NADH: ubiquinone oxidoreductase contains seven

99 subunits of NADH dehydrogenase (ND1-6 and ND4L), complex III or ubiquinol: cytochrome $c$

100 oxidoreductase consists of cytochrome b (CYTB), complex IV or cytochrome $c$ oxidase 
101 comprises three subunits of cytochrome $\mathrm{c}$ oxidase (COX1-COX3) and complex $\mathrm{V}$ or ATP

102 synthase includes two subunits of the ATPase (ATP6 and ATP8). The mitochondrial PCGs have

103 generally been supposed to be evolving under neutral or nearly neutral selection (Ballard \&

104 Kreitman, 1995). Although it has been suggested that these genes are likely to be under strong

105 purifying selection considering their functional importance, the selective pressures might vary

106 even among closely related species and be influenced by environmental conditions (Meiklejohn,

107 Montooth \& Rand, 2007). The mitogenomes also encode the small and large subunit rRNAs

$108(r r n L$ and $r r n S)$ and twenty-two tRNA genes for the translation process of PCGs. In general, they

109 harbour a single large non-coding region containing control elements necessary for replication

110 and transcription (Boore, 1999). Mitogenomes have become widely used tools in recent

111 phylogeny, phylogeography and molecular dating analyses in various taxa, because of their (1)

112 relatively small size, (2) the high copy number, (3) maternal inheritance type and (4) relatively

113 rapid rate of evolutionary change (Moritz, Dowling \& Brown, 1987; Gray, 1989). The sequence

114 information of mitogenomes has also been used in reconstructing phylogenies of several

115 taxonomic groups within/including Gastropoda (White et al., 2011; Stöger \& Schrödl, 2013;

116 Sevigny et al., 2015; Uribe et al., 2016a,b; Romero, Weigand \& Pfenninger, 2016; Yang et al.,

117 2019). Although there have been some criticisms about the usage of mitogenomes in

118 construction of gastropod phylogeny because of long branch attraction, substitution saturation

119 and strand-specific skew bias (Stöger \& Schrödl, 2013), within the recently diversified lineages

120 of gastropods, the use of mitogenomes resulted in highly resolved phylogenies (Williams, Foster

121 \& Littlewood, 2014; Osca, Templado \& Zardoya, 2014). Besides the use of the mitogenome in

122 sequence-based phylogenies, mitogenome rearrangements can also provide phylogenetic signals

123 (Grande, Templado \& Zardoya, 2008; Stöger \& Schrödl, 2013; Xie et al., 2019b). Although the 
124 mitogenome is widely used in phylogeny of many gastropod groups (Arquez, Colgan \& Castro,

125 2014; Osca, Templado \& Zardoya, 2014; Sevigny et al., 2015; Uribe, Zardoya \& Puillandre,

126 2018), there are limited numbers of reported stylommatophoran mitogenomes and phylogenetic

127 studies in Stylommatophora in terms of usage of mitogenome sequence and rearrangement

128 (Romero, Weigand \& Pfenninger, 2016; Xie et al., 2019a; Yang et al., 2019). To date, complete

129 or nearly complete mitogenomes have been reported for only 34 stylommatophoran species

130 (NCBI, September, 2019).

131 In this study, we sequenced and annotated the complete mitogenome of Arion vulgaris Moquin-

132 Tandon, 1855 (Gastropoda: Stylommatophora), which is considered as a serious invasive pest

133 both in agriculture and private gardens. We compared it with the mitogenome of its congener

134 Arion rufus (Linnaeus, 1758), and with all other previously reported stylommatophoran

135 mitogenomes. We also reconstructed a phylogeny from stylommatophoran mitogenomes to

136 estimate the phylogenetic position of $A$. vulgaris and to test the informativeness of mitogenome

137 data in the reconstruction of Stylommatophora phylogeny. In addition, we obtained a dated

138 phylogeny using this mitogenome dataset and fossil calibrations to estimate divergence times

139 within Stylommatophora. Furthermore, selection analyses were performed to investigate the role

140 of different selective forces shaping stylommatophoran mitogenomes. Finally, we compared the

141 mitogenome organisations of stylommatophoran species using a comparative and phylogeny

142 based method and tried to uncover the evolutionary pathways of mitogenome rearrangements. 
144 MATERIALS AND METHODS

145 Specimen collection and DNA extraction

146 The specimen of A. vulgaris was collected from the garden of the Zoologische Staatssammlung

147 München (ZSM), Germany. Total genomic DNA was extracted from mantle tissue using CTAB

148 method (Doyle \& Doyle, 1987).

149

150 Mitogenome sequencing, annotation and analyses

151 The whole-genome sequencing was conducted with $150 \mathrm{bp}$ pair-end reads on the Illumina

152 Hiseq4000 Platform (Illumina, San Diego, CA) using 350 bp insert size libraries. Raw reads

153 were processed by removing low quality reads, adapter sequences and possible contaminated

154 reads using Fastp v0.20.0 (Chen et al., 2018) and Lighter v1.0.7 (Song, Florea \& Langmead,

155 2014). In total, about 7.5G high quality base pairs of sequence data were obtained and the

156 mitogenome was assembled using the MitoZ software (Meng et al., 2019), followed by manual

157 curation using Geneious R9 (Kearse et al., 2012).

158 The annotation of tRNA genes of the A. vulgaris mitogenome was performed using MITOS

159 (http://mitos.bioinf.uni-leipzig.de/index.py) (Bernt et al., 2013b) and ARWEN web servers

160 (Laslett \& Canbäck, 2008) based on their secondary structures and anticodon sequences. The

161 locations and boundaries of PCGs and rRNA genes were identified manually by comparing with

162 the A. rufus (KT626607) homologous gene sequences. The visualization of the secondary

163 structure of tRNA genes was performed using VARNA v3-93 (Darty, Denise \& Ponty, 2009)

164 and RNAviz 2.0.3 (De Rijk, Wuyts \& De Wachter, 2003). Intergenic spacers and overlapping

165 regions between genes were estimated manually. The largest non-coding region was defined as

166 control region and the Mfold server (Zuker, 2003) was used to predict the secondary structure of 
167 this region. The "palindrome" tool within the European Molecular Biology Open Software Suite

168 (EMBOSS) (Rice, Longden \& Bleasby, 2000) was used for searching the palindromic sequences

169 in the control region. Finally, the complete mitogenome of $A$. vulgaris was deposited in

170 GenBank under accession number MN607980. The mitogenome of $A$. vulgaris is visualized

171 using OrganellarGenomeDRAW (OGDRAW) (Greiner, Lehwark \& Bock, 2019).

172 The nucleotide compositions, average nucleotide and amino acid sequence divergences and the

173 relative synonymous codon usages (RSCU) of PCGs were computed using MEGA v7.0 (Kumar,

174 Stecher \& Tamura, 2016). The strand asymmetries were calculated according to the following

175 formulas: AT-skew $=[\mathrm{A}-\mathrm{T}] /[\mathrm{A}+\mathrm{T}]$ and $\mathrm{GC}$-skew $=[\mathrm{G}-\mathrm{C}] /[\mathrm{G}+\mathrm{C}]($ Perna \& Kocher, 176 1995).

178 Phylogenetic and comparative analyses

179 Alignment and model selection

180 Phylogenetic and comparative analyses were performed using the mitogenome dataset of 35

181 stylommatophoran species representing 18 families, and using one species from

182 Systellommatophora, one species from Hygrophila, and one species from Ellobioidea as

183 outgroups (Table 1). Each tRNA and rRNA gene was aligned individually using MAFFT (Katoh

184 \& Standley, 2013) algorithm in Geneious R9 (Kearse et al., 2012). The alignment of nucleotide

185 sequences of each PCG was performed using MAFFT algorithm and the "translation align"

186 option implemented in Geneious R9. The final alignment files were then concatenated using

187 SequenceMatrix v.1.7.8 (Vaidya, Lohman \& Meier, 2011). The optimal partitioning scheme and

188 substitution models were inferred by PartitionFinder v1.1.1 (Lanfear et al., 2012) using the

189 Bayesian Information Criterion (BIC) and the "greedy" algorithm with the option of "unlinked" 
190 branch lengths. The best-fit partitioning scheme and nucleotide substitution models were used in

191 phylogenetic analyses (Table S1).

192

193 Assessing the substitution saturation level

194 The substitution saturation levels in different genes and codon positions were estimated

195 comparing the uncorrected p-distances and the distances calculated by applying the GTR $+\mathrm{G}+\mathrm{I}$

196 evolutionary model selected based on the BIC using jModelTest v2.1.7 (Darriba et al., 2012). All

197 genetic distances were computed with PAUP v4.0 b10 (Swofford, 2002).

198

199

Phylogenetic reconstruction

200 Two different datasets were created for phylogenetic analyses to test the influence of saturated

201 genes and codon positions: (1) 13 PCGs including all codon positions plus the 22 tRNAs and two

202 rRNAs (P123RNA) and (2) PCGs excluding the five saturated genes and third codon positions,

203 plus 22 tRNAs and two rRNAs (8P12RNA, Table S2). Maximum likelihood (ML) trees were

204 constructed with RAxML v8.0.9 (Stamatakis, 2014) implemented in Geneious R9 applying the

205 best-fit evolutionary model for each partition under 1000 bootstrap replicates. For Bayesian

206 Inference (BI) analyses, MrBayes v3.2.2 (Ronquist et al., 2012) was employed with two

207 independent runs of 10 million generations with four Markov chains (three cold, one heated),

208 sampling every 1000 generations and a burn-in of $25 \%$ trees. The stationarity of the chains was

209 assessed using the program Tracer v1.7 (Rambaut et al., 2018). The consensus phylogenetic trees

210 were visualized using FigTree v1.4.0 (Rambaut, 2012).

211

Peer) reviewing PDF | (2019:10:42413:1:0:NEW 23 Dec 2019) 


\section{Divergence time estimation}

213 MCMCTree program implemented in the Phylogenetic Analysis by Maximum Likelihood

214 (PAML) package v4.9 (Yang, 2007) was used for Bayesian estimation of divergence times of

215 each species. Substitution rate per site was estimated by BASEML and was used to set the prior

216 for the mean substitution rate in the Bayesian analysis. MCMC was run by $50 \times 10000$ iterations

217 with the REV substitution model. The soft bounds of Helix pomatia + Cornu aspersum

218 [divergence time between 34 million years ago (Ma) and $42 \mathrm{Ma}$ ], Mastigeulota kiangsinensis +

219 (Dolicheulota formosensis + (Aegista aubryana + Aegista diversifamilia)) (divergence time

220 between $25 \mathrm{Ma}$ and $51 \mathrm{Ma}$ ), and Camaena cicatricosa + Camaena poyuensis (divergence time

221 between $16 \mathrm{Ma}$ and $39 \mathrm{Ma}$ ) were used as external calibrations (Razkin et al., 2015) and the

222 estimated nodal age of Tectipleura [244 Ma (210-279 Ma)] was used for the calibration of the

223 root (Kano et al., 2016).

224

225 Selection analyses

226 The CODEML implemented in PAML was used to estimate the ratio of

227 nonsynonymous/synonymous substitution rate $(\omega=\mathrm{dN} / \mathrm{dS})$ and to explore the role of different

228 selective constraints working on each PCG under the one-ratio model (Model A: model=0,

229 NSsites $=0$, fix_omega $=0$, omega $=1$ ). Gaps and ambiguous sites of sequence alignments were

230 included in the analyses. For each PCG, likelihood ratio tests (LRTs) were used to compare the

231 null neutral model (Model B: $\operatorname{model}=2$, NSsites $=2$, fix_omega $=1$, omega $=1)$ against

232 alternative models of branch-specific positive selection (Model C: $\operatorname{model}=2, \mathrm{NSsites}=2$,

233 fix_omega=0, omega=1.5). The Bayes Empirical Bayes (BEB) algorithm in CODEML was used

234 to detect the positively selected sites. Furthermore, the adaptive branch-site random effects 
235 likelihood (aBSREL) (Smith et al., 2015) implemented in DATAMONKEY webserver (Weaver

236 et al., 2018) was used to search the signatures of episodic positive diversifying selection testing

237 each branch. In addition, mixed effects model of evolution (MEME) (Murrell et al., 2012) was

238 used to detect episodic or diversifying selection at individual sites and a fast, unconstrained

239 Bayesian approximation for inferring selection (FUBAR) (Murrell et al., 2013) was used for

240 providing additional support to the detection of sites evolving under positive or negative

241 selection. Each PCG was also evaluated in terms of properties and magnitude of amino acid

242 changes using TreeSAAP v3.2 (Woolley et al., 2003), which uses 31 properties of amino acids

243 and categorizes the degree of substitutions to eight categories (1-8).

245 Comparison of mitogenome organizations

246 Mitogenome organizations and gene rearrangements of stylommatophoran species were analysed

247 via the CREx web server (http://pacosy.informatik.uni-leipzig.de/crex) (Bernt et al., 2007). The

248 gene orders of ancestral nodes were reconstructed using the Maximum Likelihood for Gene

249 Order Analysis (MLGO, http://geneorder.org/) (Hu, Lin \& Tang, 2014) with the input tree

250 obtained by phylogenetic approaches, and the orders of the protein coding, rRNA and tRNA

251 genes were compared with the inferred ancestral mitogenomes. A distance matrix was calculated

252 based on number of common intervals, and the output diagram visually examined to identify

253 shared and/or derived gene rearrangements as well as mechanisms of rearrangements. 
255 RESULTS AND DISCUSSION

\section{Mitogenome characteristics and nucleotide composition}

257 The complete mitogenome sequence of $A$. vulgaris was obtained with a length of $14,547 \mathrm{bp}$

258 (Table 2) and its size was within the range of the those of other reported stylommatophoran

259 mitogenomes, varying between 13,797 bp in Camaena poyuensis and 16,879 bp in Partulina

260 redfieldi (Price et al., 2018). It includes the entire set of 37 mitochondrial genes: 13 PCGs, 22

261 tRNAs and two rRNAs. Twenty-four genes were located on the $\mathrm{J}$ strand, while the remainings

262 were encoded by the opposite $\mathrm{N}$ strand (Table 2, Fig. 1).

263 The nucleotide composition of $A$. vulgaris mitogenome was distinctly biased towards A and $\mathrm{T}$,

264 with a $70.20 \% \mathrm{~A}+\mathrm{T}$ content, and comparable to other reported stylommatophoran

265 mitogenomes, varying between 59.79\% A+T in Cepea nemoralis (Yamazaki et al., 1997) and

$26680.07 \%$ A + T in Achatinella mustelina (Price et al., 2016a) (Tables 3 and S3). A bias towards A

267 and T nucleotides was also observed in PCGs of the $A$. vulgaris mitogenome with a $69.34 \% \mathrm{~A}+$

268 T content (Table 3$)$. The $A+T$ content of the $3^{\text {rd }}$ codon position $(79.64 \%)$ was higher than those

269 of the $2^{\text {nd }}(64.21 \%)$ and $1^{\text {st }}$ codon positions $(64.18 \%)$. Similar to other reported

270 stylommatophoran mitogenomes (Table S3), the AT- and GC-skews were found slightly

271 negative $(-0.0756)$ and positive $(0.0431)$ in the whole mitogenome of A. vulgaris, respectively.

272 A pronounced T and G skew was also observed in all PCGs $(-0.1508,0.0472)$, PCGs on the

273 majority strand $(-0.1447,0.0596)$, and tRNA genes $(-0.0010,0.1582)$ (Table 3$)$. The T- and

$274 \mathrm{G}$-skewed mitogenome of $A$. vulgaris might be explained by the spontaneous deamination of

275 cytosine during replication and transcription processes (Reyes et al., 1998). The PCGs encoded

276 on the minority strand displayed a $\mathrm{T}-$ and $\mathrm{C}-$ skewed pattern $(-0.1783$ AT - skew, -0.0065 
277 GC-skew), contrary to the expected high rates of Ts and Gs on the minority strand for most of

278 the metazoans (Hassanin, Léger \& Deutsch, 2005).

280 Protein coding genes and codon usage

281 In comparison, the lengths of the PCGs of $A$. vulgaris mitogenome were within the range of

282 those of other stylommatophoran mitochondrial PCGs. The ND4 gene was the most variable

283 gene in length and has a variability of 53 codons among stylommatophorans (419 codons in

284 Microceramus pontificus and 472 codons in Orcula dolium). The most conserved gene in length

285 was $C O X 1$ and it exhibits variability with only 16 codons between species of Stylommatophora

286 (501 codons in Achatinella mustelina and 517 codons in Achatina fulica). Compared with the

287 mitogenome of $A$. rufus, the lengths of PCGs of $A$. vulgaris were distinct except for $C O X 1$,

$288 C O X 2, C Y T B$ and ND1 genes. The ND6 gene was the most variable gene in length and was

289 longer in the A. vulgaris mitogenome by 11 codons. Based on the amino acid identities, the most

290 conserved PCG was COX1 (56.45\%) whereas the least conserved was ND6 (11.92\%) among the

291 stylommatophoran mitogenomes. The most conserved PCG was COX1 (97.45\%) whereas the

292 least conserved was ATP8 $(68.18 \%)$ based on the amino acid identities between the two Arion

293 mitogenomes (Table S4).

294 In the A. vulgaris mitogenome, most of the PCGs initiated with typical ATN start codon, except

295 for $C O X 1, N D 5$ and ATP8 genes which use TTG, ACA and GTG triplets as start codons,

296 respectively (Table 2). The TTG and GTG start codons are also accepted as canonical start

297 codons for invertebrate mitogenomes (Yang et al., 2019), however, ACA as start codon for ND5

298 gene was reported for the first time for stylommatophoran mitogenomes. Most of the PCGs were

299 inferred to use TAR as termination codon, except for $N D 4 L$ and $C O X 3$ which have an 
300 abbreviated $\mathrm{T}-$ termination codon and their products are probably completed via post-

301 transcriptional polyadenylation (Anderson et al., 1981; Ojala, Montoya \& Attardi, 1981).

302 The most frequently used amino acids by the PCGs of the mitogenomes of A. vulgaris and A.

303 rufus were leucine (16.71\% and $15.91 \%$ respectively) and serine $(10.33 \%$ and $10.18 \%$

304 respectively), similar to PCGs of the mitogenome of other stylommatophoran species (Leu

$30516,60 \%$, Ser $10.21 \%$ on average). The codons rich in A and T, such as UUA-Leu, AUU-Ile,

306 UUU-Phe, AUA-Met, UAU-Tyr, were the most frequently used codons in all

307 stylommatophoran mitochondrial PCGs. The codons rich in terms of G and C content, CGC-

308 CGG-Arg, CAG-Gln, UGC-Cys, CUC-Leu and UCG-Ser were rarely used in both Arion

309 mitogenomes (Table S5, Fig. 2). CGN-Arg, CCS-Pro, GCS, UCG and UGC codons are seldom

310 used or never used also in the stylommatophoran mitogenomes and reflected a significant

311 relationship between codon usage and nucleotide content (Table S5).

\section{3 tRNA and rRNA genes}

314 All of the tRNA genes could be folded into a usual clover-leaf secondary structure, except for

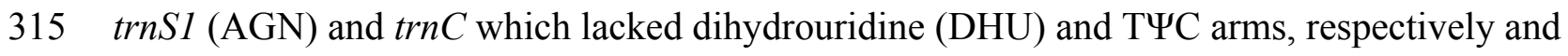

316 formed simple loops (Fig. S1). Their lengths ranged between $57 \mathrm{bp}(\operatorname{trn} C)$ and $78 \mathrm{bp}(\operatorname{trn} G)$, with

317 an average $72.72 \% \mathrm{~A}+\mathrm{T}$ content. 26 mismatched positions were observed in stem regions and

318 all of the mismatches were G-U pairs (Fig. S1).

319 The exact boundaries of rRNA genes were determined as being bounded by the adjacent tRNA

320 genes. The $r r n L$ gene was located between $\operatorname{trn} V$ and $\operatorname{trn} L 1$ genes, and the $r r n S$ gene was located

321 between $\operatorname{trn} Q$ and $\operatorname{trn} M$ genes. The length of the $r r n L$ gene was $1013 \mathrm{bp}$, with a $71.17 \% \mathrm{~A}+\mathrm{T}$

322 content, while that of $r r n S$ gene was $747 \mathrm{bp}$, with a $71.75 \% \mathrm{~A}+\mathrm{T}$ content. These were 
323 comparable in ranges to homologous genes in other reported stylommatophoran species, ranging

324 from 605 to $1215 \mathrm{bp}$ in $r r n L$ and from 564 to $857 \mathrm{bp}$ in $r r n S$.

325

326 Non-coding and overlapping regions

327 The total length of intergenic regions in the $A$. vulgaris mitogenome was $670 \mathrm{bp}$ in 16 locations

328 ranging between 1 and $370 \mathrm{bp}$ (Table 2). In general, the largest non-coding region in the animal

329 mitogenomes is considered to contain the signals for replication and transcription, and so called

330 as the control region (Wolstenholme, 1992). The possible candidate for the control region in $A$.

331 vulgaris mitogenome was the largest non-coding region located between $\operatorname{trn} Y$ and $\operatorname{trn} G$ genes

332 with $370 \mathrm{bp}$ in length. This sequence did not give BLAST hits with other putative CRs of other

333 molluscan mitogenomes, however a part of the sequence with $67 \mathrm{bp}$ in length displayed $79.11 \%$

334 sequence similarity with the mitochondrial control region of an amphibian species (Indotyphlus

335 maharashtraensis, KF540157). Nucleotide composition of this region was slightly biased

336 towards $\mathrm{A}+\mathrm{T}$ with a $69.73 \% \mathrm{~A}+\mathrm{T}$ content. The putative control region had a nine bp poly- $\mathrm{T}$

337 stretch and formed a stable secondary structure comprising seven stems and loops (Fig. 3).

338 Furthermore, this sequence also contained a lot of palindromic sequences which are varying

339 between 4 and $8 \mathrm{bp}$, but tandemly repeated sequences were not found.

340 The second largest non-coding region was found between $\operatorname{trn} W$ and $\operatorname{trn} Y$ with a length of $91 \mathrm{bp}$

341 (Table 2). The $\mathrm{A}+\mathrm{T}$ composition of the sequence was higher than that of whole genome and

342 putative control region with an $86.81 \% \mathrm{~A}+\mathrm{T}$. This non-coding region also contained a seven $\mathrm{bp}$

343 poly-A stretch and was folded into a secondary structure with two stem and loops. This

344 secondary structure forming AT-rich sequence might function as the origin of the second strand

345 (Wolstenholme, 1992). 
346 Eleven overlapping regions with a total length of $164 \mathrm{bp}$ were found throughout the mitogenome

347 of $A$. vulgaris. The largest overlapping region was $41 \mathrm{bp}$ in length and located between ND6 and

348 ND5 genes, while the second largest was $32 \mathrm{bp}$ and located between trnL2 and ATP8 (Table 2).

\section{Phylogeny and divergence times of stylommatophoran species}

351 Regression analyses of pairwise distances revealed that the $1^{\text {st }}$ and $2^{\text {nd }}$ codon positions of $A T P 8$,

352 ND2, ND3, ND4L and ND6 genes, as well as the $3^{\text {rd }}$ codon positions of all PCGs were saturated

353 (Table S2). Four phylogenetic reconstruction analyses were performed with combination of

354 inference methods and different data matrices to test the influence of inference methods and 355 saturation level of genes/codon positions on tree topology and nodal support. Three different tree 356 topologies were obtained as the results of these analyses, and topologies were sensitive to both 357 inference methods and exclusion of saturated genes/ codon positions (Figures 4 and S2-4). Nodal 358 support values were always higher in BI trees than ML trees of the corresponding dataset. The 359 usage of all mitochondrial genes and codon positions (P123RNA dataset) under both approaches 360 resulted with identical tree topology (Figures S3 and S4), which were similar to the results of Yang 361 et al (2019) obtained using only amino acid sequences of mitochondrial PCGs. The results of these 362 analyses supported the monophyly of all included superfamilies with high nodal supports except 363 for the superfamily Helicoidea which recovered with low nodal support [Bayesian Posterior

364 Probability $(\mathrm{BPP})=0.75$, Bootstrap support $(\mathrm{BS})=58 \%$ ] and recovered Arionoidea superfamily as

365 sister group to Urocoptoidea $+($ Polygyroidea + Helicoidea $)$ clade $(\mathrm{BPP}=1.00, \mathrm{BS}=100 \%)$, and

366 Succineoidea + Orthalicoidea clade was recovered as sister group to Arionoidea + (Urocoptoidea

$367+($ Polygyroidea + Helicoidea $)(\mathrm{BPP}=1.00, \mathrm{BS}=50 \%)$. The $\mathrm{ML}$ and $\mathrm{BI}$ analyses performed using 368 the dataset constructed with the removal of the saturated PCGs and codon positions (8P12RNA) 
369 resulted in two different tree topologies (Figures 4 and S2). The phylogenetic tree obtained from

370 ML analysis did not support the monophyly of the superfamily of Helicoidea and the superfamily

371 of Polygyroidea placed within the superfamily of Helicoidea (BS=61\%, Fig. S2). A highly

372 resolved tree with higher nodal support values was obtained from the BI approach of the dataset

373 8P12RNA, and hence considered as most reliable tree for discussion. The results confirmed the

374 taxonomic position of $A$. vulgaris as sister species to A. rufus and recovered the monophyly of the

375 Arionoidea superfamily (Arionidae + Philomycidae) with high support values ( $\mathrm{BPP}=1.00)$. A well-

376 supported sister group relationship between Arionoidea and Orthalicoidea was recovered

$377(\mathrm{BPP}=0.98)$ for the first time. However, previous studies using different datasets and sampling of

378 taxa have proposed different sister groups with Arionoidea superfamily. Wade, Mordan \& Naggs,

379 (2006) have found the superfamily Limacoidea as sister group to the superfamily Arionoidea using

380160 stylommatophoran species, however they used only 823 nucleotides from rRNA gene-cluster.

381 Holznagel, Colgan \& Lydeard, (2010) have proposed a sister group relationship between

382 Arionoidea and Limacoidea + Zonitoidea based on the 28S rRNA sequences using seven species

383 from Stylommatophora. The sister group relationships between Arionoidea and Urocoptoidea +

384 Enoidea + Helicoidea (Jörger et al., 2010) or Limacoidea + (Succineoidea + Helicoidea) (Dayrat

385 el al., 2011) have also been suggested by previous studies using relatively longer DNA sequences,

386 however in both studies, only five stylommatophoran species were included for phylogenetic

387 analyses. Furthermore, Xie et al., (2019b) have proposed sister group relationship between

388 Arionoidea and Succineoidea using only amino acid dataset of mitochondrial PCGs, and stated it

389 might be an artefact of poor taxon sampling.

390 In the phylogenetic tree obtained from 8P12RNA under BI approach, the monophyly of all

391 included families and superfamilies were also supported with high support values except for the 
392 superfamily Helicoidea which supported with a low nodal support (BPP=0.82) (Fig. 4).

393 Arionoidea + Orthalicoidea clade was recovered as sister group to Succineoidea $+($ Urocoptoidea

$394+($ Polygyroidea + Helicoidea)). The tree (Fig. 4) also recovered Deroceras reticulatum

395 (Limacoidea: Agriolimacidae) at the most basal placement and did not support the monophyly of

396 the suborder Helicina similar to the tree in Yang et al. (2019).

397 A chronogram for Stylommatophora divergence times based on the obtained tree topology is

398 shown in Figure 5. According to our divergence time analysis, the crown age of

399 stylommatophorans was estimated as $138.55 \mathrm{Ma}(180.8-107.4 \mathrm{Ma}, 95 \% \mathrm{CI})$ corresponding to

400 Early Cretaceous. Our estimated times for initial diversification of Stylommatophora are slightly

401 older but broadly congruent with the fossil records and previous studies (Tillier, Masselmot \&

402 Tillirt, 1996; Jörger et al., 2010; Dinapoli \& Klussmann-Kolb, 2010). Although Solem \&

403 Yochelson, (1979) suggested a Paleozoic origin for Stylommatophora, the widely accepted fossil

404 records with recognizable taxa began from Late Cretaceous (Bandel \& Riedel, 1994). The

405 Cretaceous origin of stylommatophoran species was also suggested by sequence studies of $28 \mathrm{~S}$

406 rDNA fragments by Tillier, Masselmot \& Tillirt, (1996), of combined data of 18S, 28S, 16S

407 rDNA and COI by Dinapoli \& Klussmann-Kolb, (2010) and Jörger et al., (2010). The

408 diversification of the stylommatophoran species may have been influenced by the explosive

409 radiation of angiosperms and speciation by host-switching during Cretaceous (Friis, Pedersen \&

410 Crane, 2010).

411 The split time of Achatina fulica from other stylommatophoran species was inferred as 131.91

412 Ma in Early Cretaceous. The splits of the superfamilies Orthalicoidea and Arionoidea, of

413 Succineoidea from Urocoptoidea + (Polygyroidea + Helicoidea), and of Clausilioidea +

414 (Pupilloidea + Achatinelloidea) were dated to $114.18 \mathrm{Ma}$ (148.7-87.2 Ma, 95\% CI), $113.30 \mathrm{Ma}$ 
415 (146.1-87.9 Ma, 95\% CI) and 111.88 Ma (148.1-84.2 Ma, 95\% CI), respectively, coinciding to

416 the beginning of the Albian (Early Cretaceous). The crown ages of the superfamilies Arionoidea,

417 Urocoptoidea, Helicoidea and Pupilloidea were estimated corresponding to Late Cretaceous

418 (84.82, 75.23, 74.39 and 70.06 Ma, respectively). The split of the two Arion species and the

419 crown age of Achatinelloidea species were dated to $15.24 \mathrm{Ma}(30.0-7.6 \mathrm{Ma}, 95 \% \mathrm{CI})$ and 13.01

$420 \mathrm{Ma}(19.7-8.2 \mathrm{Ma}, 95 \% \mathrm{CI})$, respectively, corresponding to the Miocene. The divergence time of

421 A. vulgaris and A. rufus corresponds to one of Earth's most recent, global warming events, the

422 Mid-Miocene Climatic Optimum (MMCO, 17-14.75 Ma) (Böhme, 2003). The MMCO is

423 thought to have contributed to floristic and faunistic diversity across the world and so to animal-

424 plant interactions, correlating with the rise in temperature (Barnosky \& Carrasco, 2002; Vicentini

425 et al., 2008; Tolley, Chase \& Forest, 2008). The change of plant diversity, emergence of new

426 host plants and the relative warm period may have triggered the diversification of the two Arion

427 species. The divergence time of two polygyroid species was inferred as $0.45 \mathrm{Ma}(1.1-0.1 \mathrm{Ma}$, $42895 \% \mathrm{CI})$, in the Pleistocene.

430 Selective pressures on stylommatophoran mitogenomes

431 The $\omega$ value for each of the 13 PCGs was inferred under one-ratio model using PAML and

432 presented in Table 4. All of the $\omega$ values were extremely low $(\omega<1)$, ranging between 0.0129 for

$433 C O X 1$ and 0.2198 for $A T P 8$, reflecting that all genes were under strong purifying selection

434 consistent with the general mitogenome evolution pattern in animals (Rand, 2001; Bazin, Glemin

$435 \&$ Galtier, 2006). Although purifying selection is the predominant selective force shaping

436 stylommatophoran mitogenomes, the comparison of the null neutral model and alternative

437 branch-specific positive selection model revealed six of the PCGs (ATP6, $C O X 2, C O X 3, N D 2$, 
$438 N D 4$ and ND5) have variation in $\omega$ values along different branches. The variability in $\omega$ values

439 indicated different selective forces acting on each gene as well as each branch. A more sensitive

440 branch-site method, aBSREL, providing three states for each branch and allowing each site to

441 evolve under any kind of the value $(<1,1$ or $>1)$ (Smith et al., 2015), was used for evaluating and

442 confirming the selective forces across lineages determined by PAML analysis. All of the

443 branches in the stylommatophoran phylogeny were tested with aBSREL analysis for each PCG,

444 and the genes detected as under episodic diversifying selection were different from the results of

445 branch-site model of PAML (Table 5) except for COX3 and ND4. The aBSREL analyses

446 discovered episodic diversifying selection in ATP8 (at the branch leading to Microceramus

447 pontificus), $C O X 1$ (at the branch leading to Achatinella mustelina), COX3 (at the branch leading

448 to Arionoidea and the branch leading to Philomycus bilineatus), ND3 (at the branch leading to

449 Helicella itala), ND4 (at the branch leading to Succinea putris) and ND6 (at the branch leading

450 to Vertigo pusilla). Due to their important function, mitochondrial genes might have a few

451 positively selected sites and the signatures of purifying selection likely mask those of positive

452 selection (Meiklejohn, Montooth \& Rand, 2007; da Fonseca et al., 2008). Therefore, two

453 different methods were used to detect positive selection in addition to BEB analysis: FUBAR

454 which estimates the rates of nonsynonymous and synonymous substitutions at each codon in a

455 phylogeny, and MEME which estimates the probability for a codon to have experienced episodic

456 positive selection and allows the $\omega$ ratio to vary across branches and codons. BEB analysis

457 identified eight positively selected codons in total in three genes (ND2, ND4 and ND5), whereas

458 FUBAR defined six positively selected codons in five genes (ATP6, ATP8, COX2, CYTB and

$459 N D 4 L$ ). The MEME analysis found the signals of episodic positive selection at 22 codons in nine

460 genes $(A T P 6, A T P 8, C Y T B, N D 2-6$, and $N D 4 L)$. There was not any shared codon determined by 
461 all of the three analyses (Table 6). Only four codons in three genes were shared by the results of

462 FUBAR and MEME analyses: 44th codon in ATP8 gene, 12th codon in CYTB gene, and 13th

463 and 57th codons in ND4L gene. Therefore, we focused only on these four codons in the

464 TreeSAAP analyses. The positively selected substitution at codon 44 in ATP8 gene was the

465 change of TTA (Leu) to ATT (Ile) at branches leading to M. kiangsinensis, Cerion incanum and

466 Cerion uva. This substitution was a radical chemical change with a magnitude category of 8 and

467 had an impact on the increment of the equilibrium constant (ionization of $\mathrm{COOH}$ ). The change at

468 the codon 12 in $C Y T B$ gene was a conserved change with a magnitude category of 1 and was a

469 substitution of TTG (Leu) to ATG (Met). The positively selected substitutions in ND4L gene

470 were the change of ATT (Ile) to ATA (Met) at branch leading to H. pomatia, to GTT (Val) at

471 branch leading to $C$. nemoralis at codon 13, and the change of TTT (Phe) to AAT (Asn) at

472 branch leading to Arionidae family at codon 57 . The substitution at the 13 th codon was a radical

473 change with a magnitude category of 8 altering the equilibrium constant (ionization of $\mathrm{COOH}$ ),

474 while that at the 57 th codon was a radical change with a magnitude category of 7 and modifying

475 the solvent accessibility of the protein.

476 Consequently, six positive selected genes ( $A T P 8, C O X 1, C O X 3, N D 3, N D 4$ and ND6) detected

477 by branch-specific aBSREL approach and three genes (ATP8, CYTB and ND4L) detected by

478 codon-based BEB, FUBAR and MEME approaches were exposed to diversifying selection. Four

479 of these genes $(N D 3, N D 4, N D 4 L$ and $N D 6)$ play an important role in oxidative phosphorylation

480 and are subunits of NADH dehydrogenase (Complex I) which is the most complicated and

481 largest proton pump of the respiratory chain coupling electron transfer from NADH to

482 ubiquinone. In addition to its important role in energy production, it has been shown that

483 complex I is implicated in the regulation of reactive oxygen species (ROS) (Sharma, Lu \& Bai, 
484 2009). Substitutions in this complex might have been favoured for increasing the efficiency of

485 proton pumping or regulating the response to ROS depending varying amount of oxygen in the

486 atmosphere and adaptation to conditions in new habitats (temperature, humidity, altitude) and /

487 or hosts. $C Y T B$ gene encodes only mitogenome derived subunit of Complex III and catalyses

488 reversible electron transfer from ubiquinol to cytochrome c (da Fonseca et al., 2008). The

489 positively selected sites in complexes I and III have been suggested to contribute to

490 environmental adaptation in different groups such as mammals, birds, fishes and insects (da

491 Fonseca et al., 2008; Garvin, Bielawski \& Gharrett, 2011; Garvin et al., 2014; Melo-Ferreira et

492 al., 2014; Morales et al., 2015; Li et al., 2018). In the cytochrome $c$ oxidase complex (Complex

493 IV), $C O X 1$ protein catalyses electron transfer to the molecular oxygen; $C O X 2$ and $C O X 3$ belong

494 to the catalytic core of the complex may act as a regulator. ATP8 gene encodes the part of ATP

495 synthase (Complex V) regulating the assembly of complex (da Fonseca et al., 2008). The

496 favoured substitutions in $C O X 3$ and $A T P 8$ gene might have an impact on assembly of the

497 complexes IV and V. The positively selected substitutions and random accumulation of variation

498 in mitochondrial PCGs of stylommatophoran species thus seem to be adaptive and affecting

499 mitochondrial ATP production or protection from ROS effects, however effects of substitutions

500 should be examined in a larger sample by considering protein folding and three-dimensional

501 structure of complexes.

502

503 Gene rearrangements in stylommatophoran mitogenomes

504 The ancestral mitogenome organisation of each node in the phylogeny was inferred using the

505 maximum likelihood approach. The organisation of the hypothetical ancestral Stylommatophora

506 mitogenome (node: A34, Fig. 4) was identical with that of Deroceras reticulatum as well as 
507 those of Albinaria caerulea, Cernuella virgata and Helicella itala. The mitogenome of Achatina

508 fulica has only experienced the transposition of $\operatorname{trn} P$ to the downstream of $\operatorname{trn} A$ compared to its

509 most recent ancestral mitogenome organisation. The common ancestors of Clausilioidea +

510 (Pupilloidea + Achatinelloidea) (node: A31, Fig. 4), Orthalicoidea + Arionoidea (node: A22, Fig.

511 4), and Succineoidea $+($ Urocoptoidea $+($ Polygyroidea + Helicoidea $)$ (node: A18, Fig. 4)

512 maintained the same order of hypothetical ancestral stylommatophoran mitogenome. In the

513 mitogenome of the most recent common ancestor (MRCA) of Pupilloidea + Achatinelloidea

514 (node: A30, Fig. 4), the reversal of $\operatorname{trn} W, \operatorname{trn} G$ and $\operatorname{trn} H$ genes occurred individually and were

515 followed by the reversal of the cluster $\operatorname{trn} W$-trnG-trnH . In the superfamily Pupilloidea,

516 rearrangements of several tRNA genes were observed: the transposition of the cluster $\operatorname{trn} D$-trnC

517 to downstream of trnW in Pupilla muscorum, transpositions of cluster $\operatorname{trnH}$-trnG to downstream

518 of $\operatorname{trn} W$ and of $\operatorname{trn} T$ to upstream of $C O X 3$ in Orcula dolium, transposition of $\operatorname{trn} G$ to downstream

519 of trnW in Vertigo pusilla and the reversal of trnQ in Gastrocopta cristata. In the mitogenome of

520 the MRCA of the superfamily Achatinelloidea (node: A26, Fig. 4), $\operatorname{trnF}-\mathrm{COX2}-\operatorname{trn} Y$-trnH-trnG-

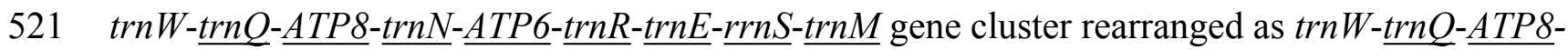

522 ATP6-trnR-trnE-rrnS-trnM-trnF-COX2-trnY-trnH-trnG-trnN via tandem duplication random

523 loss (TDRL) mechanism. The organisation of the mitogenomes of achatinelloid species nearly

524 matched with the putative ancestral order, except for Achatinella sowerbyana which has a

525 transposed position of $\operatorname{trnK}$ to downstream of $A T P 8$ and a second copy of $\operatorname{trn} L 2$, and for

526 Partulina redfieldi which has the inversion of $\operatorname{trn} E$ and $\operatorname{trn} N$ genes.

527 The mitogenome of Naesiotus nux has almost the same organisation with its MRCA (node: A22,

528 Fig. 4), except for the second inverted copy of $N D 4 L$ located between $\operatorname{trnL} 1$ and $\operatorname{trn} P$. The

529 MRCA of the superfamily Arionoidea (node: A21, Fig. 4) had also identical mitogenome 
530 organisation with the ancestor of Stylommatophora, and the MRCAs of the families Arionidae

531 (node: A19, Fig. 4) and of Philomycidae (node: A20, Fig. 4) were derived from this ancestor.

532 The mitogenome of node A19 had shuffled positions of $\operatorname{trn} Y$ and $\operatorname{trn} W$, and also transpositions of

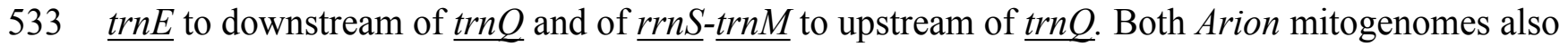

534 shared this mitogenome organisation and the rearranged orders of $\operatorname{trn} W$-trn $Y$ and $\operatorname{trn} E-\operatorname{trn} Q-r r n S$ -

535 trnM-trnL2-ATP8-trnN-ATP6-trnR clusters seem to be synapomorphies of this genus. The

536 mitogenome organisation of the node A20 was quite different from those of other

537 stylommatophoran species, which had rearranged positions of almost all genes between $C O X 1$

538 and trnI via two-steps TDRL, and two Philomycidae species also had identical organisation

539 except for Philomycus bilineatus had a second copy of $\operatorname{trnC}$ located downstream of the original

540 copy.

541 The mitogenome of Succinea putris has experienced the transpositions of trnF to upstream of

$542 \operatorname{trn} D$ and of $\operatorname{trn} W$ to upstream of $\operatorname{trn} Y$, and also reverse transposition of the cluster $\operatorname{trn} W$-trn $Y$ to

543 the upstream of $\underline{N D 3}$. The MRCA of the all urocoptoid species (node: A16, Fig. 4) only had the

544 reversal of $\operatorname{trn} Q$ gene from minor to major strand and M. pontificus has also maintained the

545 identical arrangement. The four step requiring rearranged gene cluster was identified in the

546 mitogenome of the MRCA of the genus Cerion (node: A15, Fig. 4): (i) reversal of trnV-rrnL-

$547 \operatorname{trnL1}$, (ii) reversal of $\operatorname{trn} P$, (iii) reversal of $\operatorname{trn} A$, and (iv) reversal of the cluster $\operatorname{trn} L 1-r r n L-\operatorname{trn} V$ -

$548 \operatorname{trn} P$-trnA. The mitogenome organisation remained the same in all three Cerion species and the

549 rearranged state of trnA-trnP-trnV-rrnL-trnL1 cluster might be a synapomorphy for this genus.

550 The MRCAs of the polygroid species (node: A12, Fig. 4) and Camaenidae + Bradybaenidae

551 (node: A5, Fig. 4), as well as the Polygyra cereolus and Praticolella mexicana, had the

552 transposed position of $\operatorname{trn} G-\operatorname{trn} H$ to the upstream of $\operatorname{trn} Y$. The rearrangement of this cluster as 
553 trnG-trnH-trnY could be suggested as a synapomorphy for Polygyroidea, but more sampling is

554 required to confirm its status at superfamily level. In the superfamily Helicoidea, the MRCAs of

555 Geomitridae (node: A9, Fig. 4) and Geomitridae + Helicidae (node: A10, Fig. 4) shared the

556 identical mitogenome organisation with the MRCA of Stylommatophora. Both of the

557 Geomitridae species had also same mitogenome organisation except for ATP8 in Cernuella

558 virgata, in which this gene was missing, however it seems to be likely a misannotation. The

559 mitogenome of MRCA of Helicidae species (node: A8, Fig. 4) had experienced the

560 transpositions of $\operatorname{trn} P$ and cluster $\underline{\operatorname{trn} T}-\underline{C O X 3}$ to downstream of ND6 and to upstream of $\operatorname{trnS1}$,

561 respectively. The mitogenome organisations of Helix pomatia, Cornu aspersum and Cepaea

562 nemoralis have not changed and trnA-ND6-trnP and trnS2-trnT-COX3-trnS1 gene orders might

563 be interpreted as synapomorphic for these three species. However, the individual reversals of

$564 \operatorname{trn} A, N D 6$ and $\operatorname{trn} P$ genes followed by reversal of the cluster $\underline{\operatorname{trn} A-N D 6}-\underline{\operatorname{trn} P}$, and reversal of

565 trnS1 were observed in Cylindrus obtusus mitogenome. In the mitogenomes of the species of the

566 family Camaenidae, only the transpositions of $\operatorname{trn} D$ and $\operatorname{trn} Y$ to downstream of $C O X 2$ and to

567 upstream of $\operatorname{trn} G$ were found, respectively. The arrangement of the $\operatorname{trn} C$-trnF-COX2-trnD-trnY-

$568 \operatorname{trn} G$ cluster could be considered as a synapomorphy for camaenid species, however the

569 taxonomic level of this synapomorphy need to be evaluated in a wider taxonomic range. In the

570 family of Bradybaenidae, the MRCA mitogenome had experienced only the reversal of $\operatorname{trn} W$. In

571 addition to this rearrangement, Aegista species also have the transposition of $\underline{N D 3}$ gene to the

572 downstream of $\operatorname{trn} W$ and the rearranged position of $\underline{N D 3-\operatorname{trn} W}$ cluster appears to be a

573 synapomorphy for the genus.

574 


\section{CONCLUSIONS}

576 The sequencing and annotation of the mitogenome of $A$. vulgaris and its comparison with other

577 stylommatophoran mitogenomes allow us to denote several conclusions: (i) the mitogenome

578 characteristics of $A$. vulgaris are mostly consistent with the reported stylommatophoran

579 mitogenomes, (ii) rearrangement events are detected in the $\operatorname{trn} W$-trn $Y$ and $\operatorname{trn} E$-trn $Q-r r n S$-trnM-

580 trnL2-ATP8-trnN-ATP6-trnR gene clusters which may be apomorphic for the genus Arion, but

581 further investigations are necessary, (iii) stylommatophoran mitogenome sequence information

582 without the saturated positions seems to be useful for reconstructing phylogeny and estimating

583 divergence times, and the taxon set used should be expanded, (iv) although purifying selection is

584 the dominant force in shaping the stylommatophoran mitogenomes, in the background, several

585 codons or different branches have experienced diversifying selection suggesting adaptation to 586 new environmental conditions.

\section{ACKNOWLEDGMENTS}

589 This study has received funding from the European Union's Horizon 2020 research and

590 innovation programme under the Marie Skłodowska-Curie grant agreement No 764840.

\section{REFERENCES}

592 Ahn S-J., Martin R., Rao S., Choi M-Y. 2017. The complete mitochondrial genome of the gray garden slug Deroceras reticulatum (Gastropoda: Pulmonata: Stylommatophora). Mitochondrial DNA Part B 2:255-256. DOI: 10.1080/23802359.2017.1318677.

Anderson S., Bankier AT., Barrell BG., De Bruijn MHL., Coulson AR., Drouin J., Eperon IC., Nierlich DP., Roe BA., Sanger F., Schreier PH., Smith AJH., Staden R., Young IG. 
1981. Sequence and organization of the human mitochondrial genome. Nature 290:457465. DOI: $10.1038 / 290457 \mathrm{a} 0$.

599

600

601

602

603

604

605

606

607

608

609

610

611

612

613

614

615

616

617

Arquez M., Colgan D., Castro LR. 2014. Sequence and comparison of mitochondrial genomes in the genus Nerita (Gastropoda: Neritimorpha: Neritidae) and phylogenetic considerations among gastropods. Marine Genomics 15:45-54. DOI: 10.1016/j.margen.2014.04.007.

Ballard JW., Kreitman M. 1995. Is mitochondrial DNA a strictly neutral marker? Trends in Ecology \& Evolution 10:485-8.

Bandel K. 1991. Gastropods from brackish and fresh water of the Jurassic - Cretaceous transition (a systematic reevaluation). Berliner Geowissenschaftliche Abhandlungen Reihe A Geologie und Palaeontologie 134:9-55.

Bandel K., Riedel F. 1994. The Late Cretaceous gastropod fauna from Ajka (Bakony Mountains, Hungary): A revision. Annalen des Naturhistorischen Museums in Wien. 165.

Barker GM. 2009. Gastropods on land: phylogeny, diversity and adaptive morphology. In: The biology of terrestrial molluscs. DOI: 10.1079/9780851993188.0001.

Barnosky AD., Carrasco MA. 2002. Effects of Oligo-Miocene global climate changes on mammalian species richness in the northwestern quarter of the USA. Evolutionary Ecology Research.

Bazin E., Glemin S., Galtier N. 2006. Population size does not influence mitochondrial genetic diversity in animals. Science 312:570-572. DOI: 10.1126/science.1122033. 
618 Bernt M., Bleidorn C., Braband A., Dambach J., Donath A., Fritzsch G., Golombek A., Hadrys H., Jühling F., Meusemann K., Middendorf M., Misof B., Perseke M., Podsiadlowski L., von Reumont B., Schierwater B., Schlegel M., Schrödl M., Simon S., Stadler PF., Stöger I., Struck TH. 2013a. A comprehensive analysis of bilaterian mitochondrial genomes and phylogeny. Molecular Phylogenetics and Evolution 69:352-364. DOI: 10.1016/j.ympev.2013.05.002.

Bernt M., Donath A., Jühling F., Externbrink F., Florentz C., Fritzsch G., Pütz J., Middendorf M., Stadler PF. 2013b. MITOS: Improved de novo metazoan mitochondrial genome annotation. Molecular Phylogenetics and Evolution 69:313-319. DOI: 10.1016/j.ympev.2012.08.023.

Bernt M., Merkle D., Ramsch K., Fritzsch G., Perseke M., Bernhard D., Schlegel M., Stadler 629 PF., Middendorf M. 2007. CREx: Inferring genomic rearrangements based on common intervals. Bioinformatics. DOI: 10.1093/bioinformatics/btm468.

Böhme M. 2003. The Miocene Climatic Optimum: Evidence from ectothermic vertebrates of 632 Central Europe. Palaeogeography, Palaeoclimatology, Palaeoecology. DOI:

Boore JL. 1999. Animal mitochondrial genomes. Nucleic acids research 27:1767-80.

Bouchet P., Rocroi J-P., Hausdorf B., Kaim A., Kano Y., Nützel A., Parkhaev P., Schrödl M., 636 Strong EE. 2017. Revised classification, nomenclator and typification of gastropod and monoplacophoran families. Malacologia 61:1-526. DOI: 10.4002/040.061.0201. Bioinformatics 34:i884-i890. DOI: 10.1093/bioinformatics/bty560. 
640 Darriba D., Taboada GL., Doallo R., Posada D. 2012. jModelTest 2: more models, new

641 heuristics and parallel computing. Nature Methods 9:772-772. DOI:

$642 \quad 10.1038 /$ nmeth.2109.

643 Darty K., Denise A., Ponty Y. 2009. VARNA: Interactive drawing and editing of the RNA

644 secondary structure. Bioinformatics 25:1974-1975. DOI:

$645 \quad$ 10.1093/bioinformatics/btp250.

646 Dayrat B., Conrad M., Balayan S., White TR., Albrecht C., Golding R., Gomes SR.,

647 Harasewych MG., de Frias Martins AM. 2011. Phylogenetic relationships and evolution

648 of pulmonate gastropods (Mollusca): New insights from increased taxon sampling.

649 Molecular Phylogenetics and Evolution 59:425-437. DOI:

$650 \quad$ 10.1016/j.ympev.2011.02.014.

651 Deng P-J., Wang W-M., Huang X-C., Wu X-P., Xie G-L., Ouyang S. 2016. The complete

652 mitochondrial genome of Chinese land snail Mastigeulota kiangsinensis (Gastropoda:

653 Pulmonata: Bradybaenidae). Mitochondrial DNA 27:1441-1442. DOI:

$654 \quad 10.3109 / 19401736.2014 .953083$.

655 Dinapoli A., Klussmann-Kolb A. 2010. The long way to diversity - Phylogeny and evolution of 656 the Heterobranchia (Mollusca: Gastropoda). Molecular Phylogenetics and Evolution 55:60-76. DOI: 10.1016/j.ympev.2009.09.019.

658 Doyle J., Doyle J. 1987. A rapid isolation procedure for small amounts of leaf tissue.

659 Phytochemical Bulletin 19:11-15. DOI: 10.2307/4119796. 
660 da Fonseca RR., Johnson WE., O’Brien SJ., Ramos MJ., Antunes A. 2008. The adaptive 661 evolution of the mammalian mitochondrial genome. BMC Genomics 9:119. DOI:

662 10.1186/1471-2164-9-119.

663

664

665

666

667

668

669

670

671

672

673

674

675

676

677

678

679

680
Friis EM., Pedersen KR., Crane PR. 2010. Diversity in obscurity: fossil flowers and the early history of angiosperms. Philosophical Transactions of the Royal Society B: Biological Sciences 365:369-382. DOI: 10.1098/rstb.2009.0227.

Gaitán-Espitia JD., Nespolo RF., Opazo JC. 2013. The Complete Mitochondrial Genome of the Land Snail Cornu aspersum (Helicidae: Mollusca): Intra-Specific Divergence of Protein-Coding Genes and Phylogenetic Considerations within Euthyneura. PLoS ONE 8. DOI: 10.1371/journal.pone.0067299.

Garvin MR., Bielawski JP., Gharrett AJ. 2011. Positive darwinian selection in the piston that powers proton pumps in Complex I of the mitochondria of Pacific salmon. PLoS ONE 6. DOI: 10.1371/journal.pone.0024127.

Garvin MR., Bielawski JP., Sazanov LA., Gharrett AJ. 2014. Review and meta-analysis of natural selection in mitochondrial complex I in metazoans. Journal of Zoological Systematics and Evolutionary Research 53. DOI: 10.1111/jzs.12079.

González VL., Kayal E., Halloran M., Shrestha Y., Harasewych MG. 2016. The complete mitochondrial genome of the land snail Cerion incanum (Gastropoda:

Stylommatophora) and the phylogenetic relationships of Cerionidae within Panpulmonata. Journal of Molluscan Studies 82:525-533. DOI: 10.1093/mollus/eyw017. 
681 Grande C., Templado J., Zardoya R. 2008. Evolution of gastropod mitochondrial genome 682 arrangements. BMC Evolutionary Biology 8:61. DOI: 10.1186/1471-2148-8-61.

683 684 685 686 687 688 689 690 691 692 693

Gray MW. 1989. Origin and evolution of mitochondrial DNA. Annual Review of Cell Biology. DOI: 10.1146/annurev.cb.05.110189.000325.

Greiner S., Lehwark P., Bock R. 2019. OrganellarGenomeDRAW (OGDRAW) version 1.3.1: expanded toolkit for the graphical visualization of organellar genomes. Nucleic Acids Research 47:W59-W64. DOI: 10.1093/nar/gkz238.

Groenenberg DSJ., Harl J., Duijm E., Gittenberger E. 2017. The complete mitogenome of Orcula dolium (Draparnaud, 1801); ultra-deep sequencing from a single long-range PCR using the Ion-Torrent PGM. Hereditas 154:7. DOI: 10.1186/s41065-017-0028-2.

Groenenberg DSJ., Pirovano W., Gittenberger E., Schilthuizen M. 2012. The complete mitogenome of Cylindrus obtusus (Helicidae, Ariantinae) using Illumina next generation sequencing. BMC Genomics 13. DOI: 10.1186/1471-2164-13-114.

Hassanin A., Léger N., Deutsch J. 2005. Evidence for multiple reversals of asymmetric mutational constraints during the evolution of the mitochondrial genome of Metazoa, and consequences for phylogenetic inferences. Systematic Biology 54:277-298. DOI: $10.1080 / 10635150590947843$.

Harasewych MG., González VL., Windsor AM., Halloran M. 2017. The complete mitochondrial genome of Cerion uva uva (Gastropoda: Panpulmonata: Stylommatophora: Cerionidae). Mitochondrial DNA Part B 2:159-160. DOI: 10.1080/23802359.2017.1303343. 
702 Hatzoglou E., Rodakis GC., Lecanidou R. 1995. Complete sequence and gene organization of 703 the mitochondrial genome of the land snail Albinaria coerulea. Genetics 140:13537041366 .

705 Hausdorf B. 2000. Biogeography of the Limacoidea sensu lato (Gastropoda:

706

707 Stylommatophora): vicariance events and long-distance dispersal. Journal of Biogeography 27:379-390. DOI: 10.1046/j.1365-2699.2000.00403.x.

708

709

710

711

712

713

714

715

716

717

718

719

720

721

He Z-P., Dai X-B., Zhang S., Zhi T-T., Lun Z-R., Wu Z-D., Yang T-B. 2016. Complete mitochondrial genome of the giant African snail, Achatina fulica (Mollusca: Achatinidae): a novel location of putative control regions (CR) in the mitogenome within Pulmonate species. Mitochondrial DNA 27:1084-1085. DOI: 10.3109/19401736.2014.930833.

Holznagel WE., Colgan DJ., Lydeard C. 2010. Pulmonate phylogeny based on 28S rRNA gene sequences: A framework for discussing habitat transitions and character transformation. Molecular Phylogenetics and Evolution 57:1017-1025. DOI: 10.1016/j.ympev.2010.09.021.

Hu F., Lin Y., Tang J. 2014. MLGO: phylogeny reconstruction and ancestral inference from gene-order data. BMC Bioinformatics 15:354. DOI: 10.1186/s12859-014-0354-6.

Huang C-W., Lin S-M., Wu W-L. 2015. Mitochondrial genome sequences of landsnails Aegista diversifamilia and Dolicheulota formosensis (Gastropoda: Pulmonata: Stylommatophora). Mitochondrial DNA:1-3. DOI: 10.3109/19401736.2015.1053070. 
722 Hunter SS., Settles ML., New DD., Parent CE., Gerritsen AT. 2016. Mitochondrial Genome

723 Sequence of the Galápagos Endemic Land Snail Naesiotus nux. Genome

724 Announcements 4. DOI: 10.1128/genomeA.01362-15.

725

726

727

728

729

730

731

732

733

734

735

736

737

738

739

740

741

742

Jörger KM., Stöger I., Kano Y., Fukuda H., Knebelsberger T., Schrödl M. 2010. On the origin of Acochlidia and other enigmatic euthyneuran gastropods, with implications for the systematics of Heterobranchia. BMC Evolutionary Biology. DOI: 10.1186/1471-2148$10-323$.

Kano Y., Brenzinger B., Nützel A., Wilson NG., Schrödl M. 2016. Ringiculid bubble snails recovered as the sister group to sea slugs (Nudipleura). Scientific Reports 6:30908. DOI: 10.1038/srep30908.

Katoh K., Standley DM. 2013. MAFFT Multiple Sequence Alignment Software Version 7: Improvements in Performance and Usability. Molecular Biology and Evolution 30:772780. DOI: $10.1093 / \mathrm{molbev} / \mathrm{mst} 010$.

Kearse M., Moir R., Wilson A., Stones-Havas S., Cheung M., Sturrock S., Buxton S., Cooper A., Markowitz S., Duran C., Thierer T., Ashton B., Meintjes P., Drummond A. 2012. Geneious Basic: an integrated and extendable desktop software platform for the organization and analysis of sequence data. Bioinformatics (Oxford, England) 28:16479. DOI: 10.1093/bioinformatics/bts199.

Korábek O., Petrusek A., Rovatsos M. 2019. The complete mitogenome of Helix pomatia and the basal phylogeny of Helicinae (Gastropoda, Stylommatophora, Helicidae). ZooKeys 827:19-30. DOI: 10.3897/zookeys.827.33057. 
743 Kumar S., Stecher G., Tamura K. 2016. MEGA7: Molecular Evolutionary Genetics Analysis

744 Version 7.0 for Bigger Datasets. Molecular Biology and Evolution 33:1870-4. DOI:

$745 \quad 10.1093 / \mathrm{molbev} / \mathrm{msw} 054$.

746 Lanfear R., Calcott B., Ho SYW., Guindon S. 2012. PartitionFinder: Combined selection of

747 partitioning schemes and substitution models for phylogenetic analyses. Molecular

748 Biology and Evolution 29:1695-1701. DOI: $10.1093 / \mathrm{molbev} / \mathrm{mss} 020$.

749 Laslett D., Canbäck B. 2008. ARWEN: A program to detect tRNA genes in metazoan

750 mitochondrial nucleotide sequences. Bioinformatics 24:172-175. DOI:

$751 \quad$ 10.1093/bioinformatics/btm573.

752 Li X-D., Jiang G-F., Yan L-Y., Li R., Mu Y., Deng W-A. 2018. Positive Selection Drove the Adaptation of Mitochondrial Genes to the Demands of Flight and High-Altitude Environments in Grasshoppers. Frontiers in Genetics 9. DOI:

Lin J-H., Zhou W., Ding H-L., Wang P., Ai H-M. 2016. The mitochondrial genome of the land snail Cernuella virgata (Da Costa, 1778): the first complete sequence in the family Hygromiidae (Pulmonata, Stylommatophora). ZooKeys 589:55-69. DOI:

Liu G-H., Wang S-Y., Huang W-Y., Zhao G-H., Wei S-J., Song H-Q., Xu M-J., Lin R-Q., 761 Zhou D-H., Zhu X-Q. 2012. The Complete Mitochondrial Genome of Galba pervia (Gastropoda: Mollusca), an Intermediate Host Snail of Fasciola spp. PLoS ONE 7:e42172. DOI: 10.1371/journal.pone.0042172. 
764 Meiklejohn CD., Montooth KL., Rand DM. 2007. Positive and negative selection on the 765 mitochondrial genome. Trends in Genetics: TIG 23:259-63. DOI:

766 10.1016/j.tig.2007.03.008.

767

768

769

770

771

772

773

774

775

776

777

778

779

780

781

782

783

Melo-Ferreira J., Vilela J., Fonseca MM., Da Fonseca RR., Boursot P., Alves PC. 2014. The elusive nature of adaptive mitochondrial DNA evolution of an arctic lineage prone to frequent introgression. Genome Biology and Evolution 6:886-896. DOI: 10.1093/gbe/evu059.

Meng G., Li Y., Yang C., Liu S. 2019. MitoZ: a toolkit for animal mitochondrial genome assembly, annotation and visualization. Nucleic Acids Research. DOI: 10.1093/nar/gkz173.

Minton RL., Martinez Cruz MA., Farman ML., Perez KE. 2016. Two complete mitochondrial genomes from Praticolella mexicana Perez, 2011 (Polygyridae) and gene order evolution in Helicoidea (Mollusca, Gastropoda). ZooKeys 626:137-154. DOI: 10.3897/zookeys.626.9633.

Morales HE., Pavlova A., Joseph L., Sunnucks P. 2015. Positive and purifying selection in mitochondrial genomes of a bird with mitonuclear discordance. Molecular Ecology 24:2820-2837. DOI: 10.1111/mec.13203.

Mordan P., Wade C. 2008. Heterobranchia II: The Pulmonata. In: Phylogeny and Evolution of the Mollusca. University of California Press, 409-426. DOI: 10.1525/california/9780520250925.003.0015. 
784 Moritz C., Dowling TE., Brown WM. 1987. Evolution of Animal Mitochondrial DNA:

785 Relevance for Population Biology and Systematics. Annual Review of Ecology and

786 Systematics 18:269-292. DOI: 10.1146/annurev.es.18.110187.001413.

787 Murrell B., Moola S., Mabona A., Weighill T., Sheward D., Kosakovsky Pond SL., Scheffler

788 K. 2013. FUBAR: A fast, unconstrained Bayesian approximation for inferring selection.

789 Molecular Biology and Evolution 30:1196-1205. DOI: 10.1093/molbev/mst030.

790 Murrell B., Wertheim JO., Moola S., Weighill T., Scheffler K., Kosakovsky Pond SL. 2012.

791 Detecting individual sites subject to episodic diversifying selection. PLoS Genetics

792 8:e1002764. DOI: 10.1371/journal.pgen.1002764.

793 Ojala D., Montoya J., Attardi G. 1981. tRNA punctuation model of RNA processing in human mitochondria. Nature 290:470-474. DOI: 10.1038/290470a0.

Osca D., Templado J., Zardoya R. 2014. The mitochondrial genome of Ifremeria nautilei and the phylogenetic position of the enigmatic deep-sea Abyssochrysoidea (Mollusca: Gastropoda). Gene 547:257-266. DOI: 10.1016/j.gene.2014.06.040.

Perna NT., Kocher TD. 1995. Patterns of nucleotide composition at fourfold degenerate sites of animal mitochondrial genomes. Journal of Molecular Evolution 41:353-358. DOI: 10.1007/BF01215182.

Ponder WF., Lindberg DR. 1997. Towards a phylogeny of gastropod molluscs: an analysis using morphological characters. Zoological Journal of the Linnean Society 119:83-265. DOI: $10.1006 /$ zjls.1996.0066.

804 Price MR., Forsman ZH., Knapp I., Hadfield MG., Toonen RJ. 2016a. The complete 805 mitochondrial genome of Achatinella mustelina (Gastropoda: Pulmonata: 
806

807

808

809

810

811

812

813

814

815

816

817

Stylommatophora). Mitochondrial DNA Part B 1:175-177. DOI:

10.1080/23802359.2016.1149787.

Price MR., Forsman ZH., Knapp IS., Toonen RJ., Hadfield MG. 2016b. The complete mitochondrial genome of Achatinella sowerbyana (Gastropoda: Pulmonata: Stylommatophora: Achatinellidae). Mitochondrial DNA Part B 1:666-668. DOI: $10.1080 / 23802359.2016 .1219631$.

Price MR., Forsman ZH., Knapp I., Toonen RJ., Hadfield MG. 2018. A comparison of mitochondrial genomes from five species in three genera suggests polyphyly in the subfamily Achatinellinae (Gastropoda: Pulmonata: Stylommatophora: Achatinellidae). Mitochondrial DNA Part B 3:611-612. DOI: 10.1080/23802359.2018.1473737.

Rambaut A. 2012. FigTree v1. 4.0. A graphical viewer of phylogenetic trees. Institute of Evolutionary Biology University of Edinburgh.

Rambaut A., Drummond AJ., Xie D., Baele G., Suchard MA. 2018. Posterior Summarization in Bayesian Phylogenetics Using Tracer 1.7. Systematic Biology 67:901-904. DOI: 10.1093/sysbio/syy032.

Rand DM. 2001. The units of selection on mitochondrial DNA. Annual Review of Ecology and Systematics 32:415-448. DOI: 10.1146/annurev.ecolsys.32.081501.114109.

Razkin O., Gómez-Moliner BJ., Prieto CE., Martínez-Ortí A., Arrébola JR., Muñoz B., Chueca LJ., Madeira MJ. 2015. Molecular phylogeny of the western Palaearctic Helicoidea (Gastropoda, Stylommatophora). Molecular Phylogenetics and Evolution. DOI: 10.1016/j.ympev.2014.11.014. 
827 Reyes A., Gissi C., Pesole G., Saccone C. 1998. Asymmetrical directional mutation pressure in 828 the mitochondrial genome of mammals. Molecular Biology and Evolution. DOI: 829 10.1093/oxfordjournals.molbev.a026011.

830 Rice P., Longden L., Bleasby A. 2000. EMBOSS: The European Molecular Biology Open 831 Software Suite. Trends in Genetics. DOI: 10.1016/S0168-9525(00)02024-2.

832 De Rijk P., Wuyts J., De Wachter R. 2003. RnaViz 2: an improved representation of RNA 833 secondary structure. Bioinformatics (Oxford, England) 19:299-300.

Romero PE., Weigand AM., Pfenninger M. 2016. Positive selection on panpulmonate mitogenomes provide new clues on adaptations to terrestrial life. BMC Evolutionary Biology 16:164. DOI: 10.1186/s12862-016-0735-8.

Ronquist F., Teslenko M., van der Mark P., Ayres DL., Darling A., Höhna S., Larget B., Liu 838 L., Suchard MA., Huelsenbeck JP. 2012. MrBayes 3.2: Efficient Bayesian Phylogenetic Inference and Model Choice Across a Large Model Space. Systematic Biology 61:539-

841 Roth B., Poinar GO., Acra A., Acra F. 1996. Probable Pupillid land snail of Early Cretaceous (Hauterivian) age in amber from Lebanon. Veliger 39:87-88.

843 Sevigny JL., Kirouac LE., Thomas WK., Ramsdell JS., Lawlor KE., Sharifi O., Grewal S., Baysdorfer C., Curr K., Naimie AA., Okamoto K., Murray JA., Newcomb JM. 2015. The mitochondrial genomes of the Nudibranch mollusks, Melibe leonina and Tritonia diomedea, and their impact on gastropod phylogeny. PLoS ONE 10:e0127519. DOI: 10.1371/journal.pone.0127519. 
848 Sharma L., Lu J., Bai Y. 2009. Mitochondrial Respiratory Complex I: Structure, Function and

849

850

851

852

853

854

855

856

857

858

859

860

861

862

863

864

865

866

867

868 Implication in Human Diseases. Current Medicinal Chemistry. DOI: $10.2174 / 092986709787846578$.

Smith MD., Wertheim JO., Weaver S., Murrell B., Scheffler K., Kosakovsky Pond SL. 2015. Less is more: An adaptive branch-site random effects model for efficient detection of episodic diversifying selection. Molecular Biology and Evolution 32:1342-1353. DOI: 10.1093/molbev/msv022.

Solem A., Yochelson EL. 1979. North American Paleozoic land snails, with a summary of other Paleozoic non-marine snails. Geological Survey Professional Paper.

Song L., Florea L., Langmead B. 2014. Lighter: fast and memory-efficient sequencing error correction without counting. Genome Biology 15:509. DOI: 10.1186/s13059-014-05099.

Stamatakis A. 2014. RAxML version 8: a tool for phylogenetic analysis and post-analysis of large phylogenies. Bioinformatics 30:1312-1313. DOI: 10.1093/bioinformatics/btu033.

Stöger I., Schrödl M. 2013. Mitogenomics does not resolve deep molluscan relationships (yet?). Molecular Phylogenetics and Evolution 69:376-392. DOI: 10.1016/j.ympev.2012.11.017.

Sun BN., Wei LL., Shen HD., Wu HX., Wang DF. 2016. Phylogenetic analysis of euthyneuran gastropods from sea to land mainly based on comparative mitogenomic of four species of Onchidiidae (Mollusca: Gastropoda: Pulmonata). Mitochondrial DNA Part A 27:3075-3077. DOI: 10.3109/19401736.2014.1003916. 
869 Swofford DL. 2002. Phylogenetic Analysis Using Parsimony (*and Other Methods). Version 4.

$870 \quad$ Sunderland, Massachusetts, USA: Sinauer Associates.

871 Tillier S., Masselmot M., Tillirt A. 1996. Phylogenetic relationships of the Pulmonate

872 Gastropods from rRNA sequences, and tempo and age of the Stylommatophoran

873 radiation. In: Taylor JD ed. Origin and Evolutionary Radiation of the Mollusca. Oxford:

$874 \quad$ Oxford Press, 267-284.

875 Tolley KA., Chase BM., Forest F. 2008. Speciation and radiations track climate transitions

876 since the Miocene Climatic Optimum: a case study of southern African chameleons.

877 Journal of Biogeography 35:1402-1414. DOI: 10.1111/j.1365-2699.2008.01889.x.

878 Uribe JE., Colgan D., Castro LR., Kano Y., Zardoya R. 2016a. Phylogenetic relationships

879 among superfamilies of Neritimorpha (Mollusca: Gastropoda). Molecular Phylogenetics

$880 \quad$ and Evolution 104:21-31. DOI: 10.1016/j.ympev.2016.07.021.

881 Uribe JE., Kano Y., Templado J., Zardoya R. 2016b. Mitogenomics of Vetigastropoda: insights

882 into the evolution of pallial symmetry. Zoologica Scripta 45:145-159. DOI:

$883 \quad 10.1111 /$ zsc. 12146.

884 Uribe JE., Williams ST., Templado J., Abalde S., Zardoya R. 2017. Denser mitogenomic

885 sampling improves resolution of the phylogeny of the superfamily Trochoidea

886 (Gastropoda: Vetigastropoda). Journal of Molluscan Studies 83:111-118. DOI:

$887 \quad$ 10.1093/mollus/eyw049.

888 Uribe JE., Zardoya R., Puillandre N. 2018. Phylogenetic relationships of the conoidean snails

889 (Gastropoda: Caenogastropoda) based on mitochondrial genomes. Molecular

$890 \quad$ Phylogenetics and Evolution 127:898-906. DOI: 10.1016/j.ympev.2018.06.037. 
891 Vaidya G., Lohman DJ., Meier R. 2011. SequenceMatrix: concatenation software for the fast 892 assembly of multi-gene datasets with character set and codon information. Cladistics 893 27:171-180. DOI: 10.1111/j.1096-0031.2010.00329.x.

Vicentini A., Barber JC., Aliscioni SS., Giussani LM., Kellogg EA. 2008. The age of the 895 grasses and clusters of origins of $\mathrm{C} 4$ photosynthesis. Global Change Biology. DOI:

896 10.1111/j.1365-2486.2008.01688.x.

Wade CM., Mordan PB., Clarke B. 2001. A phylogeny of the land snails (Gastropoda: Pulmonata). Proceedings of the Royal Society of London. Series B: Biological Sciences 268:413-422. DOI: 10.1098/rspb.2000.1372.

Wade CM., Mordan PB., Naggs F. 2006. Evolutionary relationships among the Pulmonate land 901 902 snails and slugs (Pulmonata, Stylommatophora). Biological Journal of the Linnean Society. DOI: 10.1111/j.1095-8312.2006.00596.x.

903

904

905

906

907

908

909

910

911

912
Wang P., Yang H., Zhou W., Hwang C., Zhang W., Qian Z. 2014. The mitochondrial genome of the land snail Camaena cicatricosa (Müller, 1774) (Stylommatophora, Camaenidae): the first complete sequence in the family Camaenidae. ZooKeys 451:33-48. DOI: 10.3897/zookeys.451.8537.

Weaver S., Shank SD., Spielman SJ., Li M., Muse S V., Kosakovsky Pond SL. 2018. Datamonkey 2.0: A modern web application for characterizing selective and other evolutionary processes. Molecular Biology and Evolution 35:773-777. DOI: 10.1093/molbev/msx335.

White TR., Conrad MM., Tseng R., Balayan S., Golding R., de Frias Martins AM., Dayrat BA. 2011. Ten new complete mitochondrial genomes of pulmonates (Mollusca: Gastropoda) 
913

914

915

916

917

918

919

920

921

922

923

924

925

926

927

928

929

930

931

932

933

and their impact on phylogenetic relationships. BMC Evolutionary Biology 11:295. DOI: 10.1186/1471-2148-11-295.

Williams ST., Foster PG., Littlewood DTJ. 2014. The complete mitochondrial genome of a turbinid vetigastropod from MiSeq Illumina sequencing of genomic DNA and steps towards a resolved gastropod phylogeny. Gene 533:38-47. DOI: 10.1016/j.gene.2013.10.005.

Wolstenholme DR. 1992. Animal Mitochondrial DNA: Structure and Evolution. International Review of Cytology 141:173-216. DOI: 10.1016/S0074-7696(08)62066-5.

Woolley S., Johnson J., Smith MJ., Crandall KA., McClellan DA. 2003. TreeSAAP: Selection on amino acid properties using phylogenetic trees. Bioinformatics 19:671-672. DOI: 10.1093/bioinformatics/btg043.

Xie J., Feng J., Guo Y., Ye Y., Li J., Guo B. 2019a. The complete mitochondrial genome and phylogenetic analysis of Nerita yoldii (Gastropoda: Neritidae). Mitochondrial DNA Part B 4:1099-1100. DOI: 10.1080/23802359.2019.1586485.

Xie G-L., Köhler F., Huang X-C., Wu R-W., Zhou C-H., Ouyang S., Wu X-P. 2019b. A novel gene arrangement among the Stylommatophora by the complete mitochondrial genome of the terrestrial slug Meghimatium bilineatum (Gastropoda, Arionoidea). Molecular Phylogenetics and Evolution 135:177-184. DOI: 10.1016/j.ympev.2019.03.002.

Yamazaki N., Ueshima R., Terrett JA., Yokobori SI., Kaifu M., Segawa R., Kobayashi T., Numachi KI., Ueda T., Nishikawa K., Watanabe K., Thomas RH. 1997. Evolution of pulmonate gastropod mitochondrial genomes: Comparisons of gene organizations of 
934

935

936

937

938

939

940

941

942

943

944

945

946

947

948

949

950

951

952

953

954

Euhadra, Cepaea and Albinaria and implications of unusual tRNA secondary structures. Genetics 145:749-758.

Yang Z. 2007. PAML 4: Phylogenetic Analysis by Maximum Likelihood. Molecular Biology and Evolution 24:1586-1591. DOI: 10.1093/molbev/msm088.

Yang X., Xie G-L., Wu X-P., Ouyang S. 2016. The complete mitochondrial genome of Chinese land snail Aegista aubryana (Gastropoda: Pulmonata: Bradybaenidae). Mitochondrial DNA Part A 27:3538-3539. DOI: 10.3109/19401736.2015.1074207.

Yang T., Xu G., Gu B., Shi Y., Mzuka HL., Shen H. 2019. The Complete Mitochondrial Genome Sequences of the Philomycus bilineatus (Stylommatophora: Philomycidae) and Phylogenetic Analysis. Genes 10:198. DOI: 10.3390/genes10030198.

Zapata F., Wilson NG., Howison M., Andrade SCS., Jörger KM., Schrödl M., Goetz FE., Giribet G., Dunn CW. 2014. Phylogenomic analyses of deep gastropod relationships reject Orthogastropoda. Proceedings of the Royal Society B: Biological Sciences 281:20141739. DOI: 10.1098/rspb.2014.1739.

Zuker M. 2003. Mfold web server for nucleic acid folding and hybridization prediction. Nucleic Acids Research. 
955 Figure 1. Mitogenome organization of Arion vulgaris. Genes transcribed from the J and N

956 strands are shown outside and inside of the circle, respectively. PCGs coding complex I,

957 complex III, complex IV and complex V components are marked with yellow, purple, pink and

958 green, respectively. rRNA genes are coloured with red and putative control region is coloured

959 with cyan, while tRNA genes are coloured with dark blue and labelled by the single letter

960 amino acid code.

961 Figure 2. Relative synonymous codon usage (RSCU) of the A. vulgaris and $A$. rufus

962 mitogenomes. Codon families are provided on the $\mathrm{x}$ axis. The stop codons are not given.

963 Figure 3. Predicted secondary structure of putative control region of $A$. vulgaris

964 mitogenome. Nucleotides are coloured as follows: Adenine is green, thymine is red, cytosine is

965 blue and guanine is black. The poly-T stretch is labelled with purple.

966 Figure 4. Stylommatophoran phylogenetic tree constructed under BI using the dataset

967 8P12RNA. Carychium tridentatum (Ellobioidea), Platevindex mortoni (Systellommatophora)

968 and Galba pervia (Hygrophila) were used as outgroup. Nodes are labelled with numbers refer

969 to hypothetical ancestral mitogenome organizations inferred by MLGO.

970 Figure 5. Dated phylogenetic tree. The axis on the bottom refers to million years. Letters in

971 the boxes refers to external calibration points. The split between $A$. vulgaris and A. rufus was

972 shown with a red bar, while the remainings were shown with blue bars. 


\section{Figure 1}

Mitogenome organization of Arion vulgaris.

Genes transcribed from the J and N strands are shown outside and inside of the circle, respectively. PCGs coding complex I, complex III, complex IV and complex V components are marked with yellow, purple, pink and green, respectively. rRNA genes are coloured with red and putative control region is coloured with cyan, while tRNA genes are coloured with dark blue and labelled by the single letter amino acid code. 


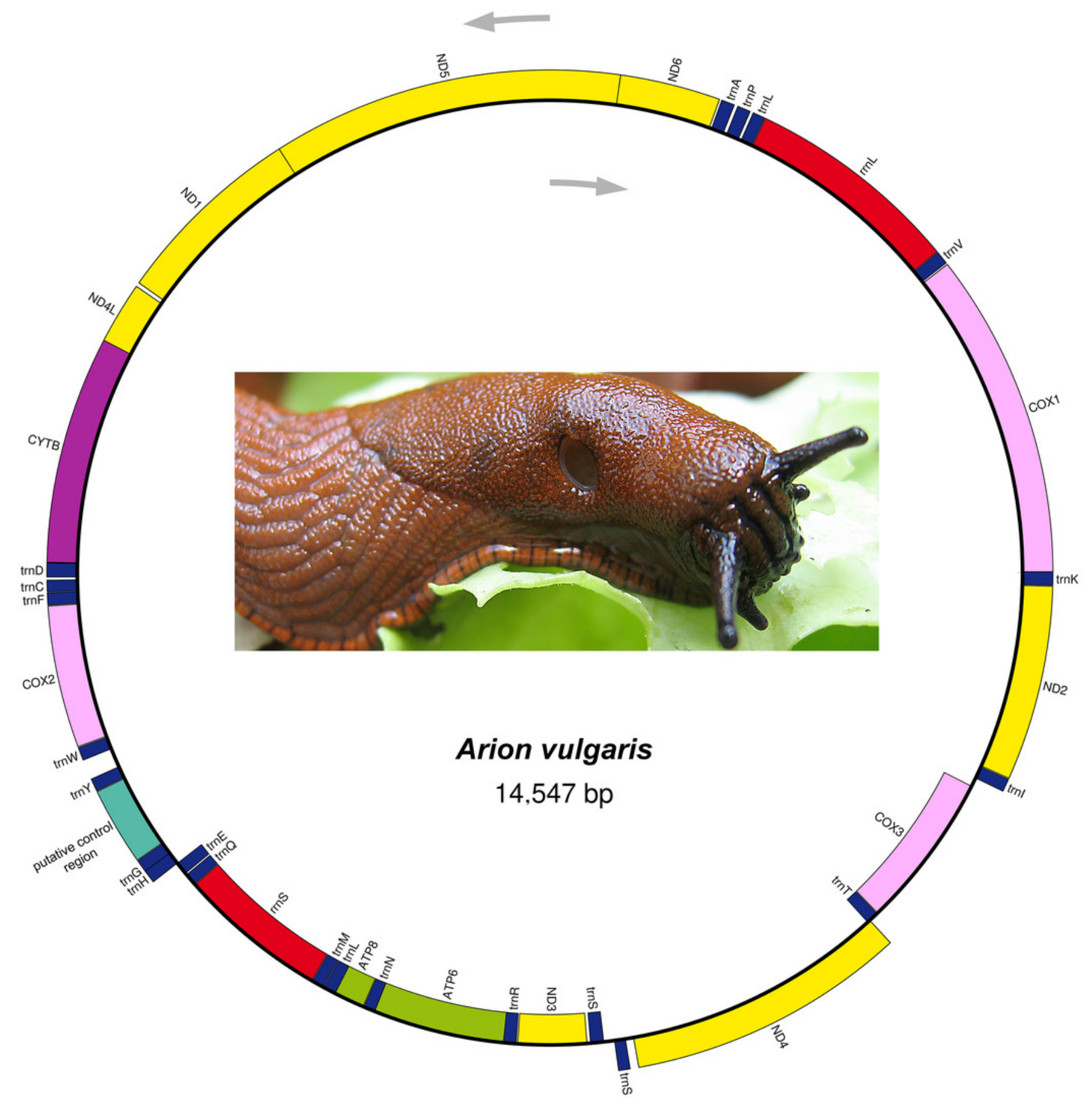


Figure 2

Relative synonymous codon usage (RSCU) of the $A$. vulgaris and $A$. rufus mitogenomes.

Codon families are provided on the $x$ axis. The stop codons are not given.

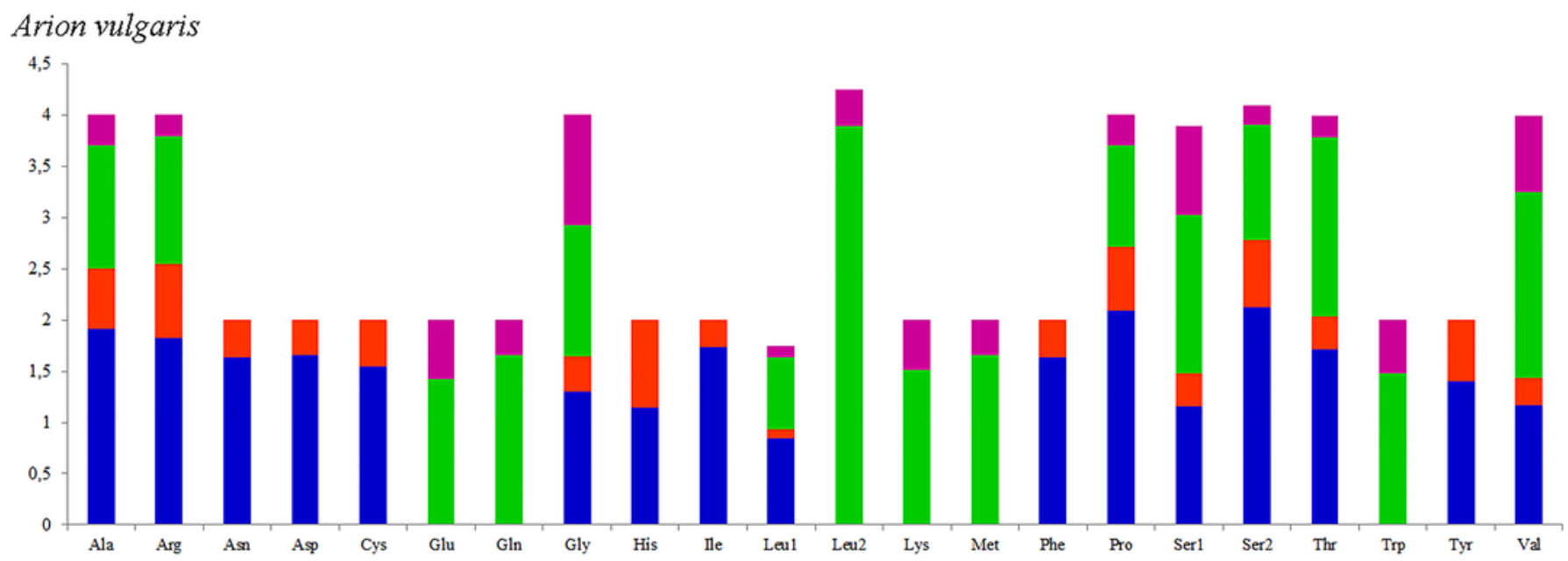

Arion rufus

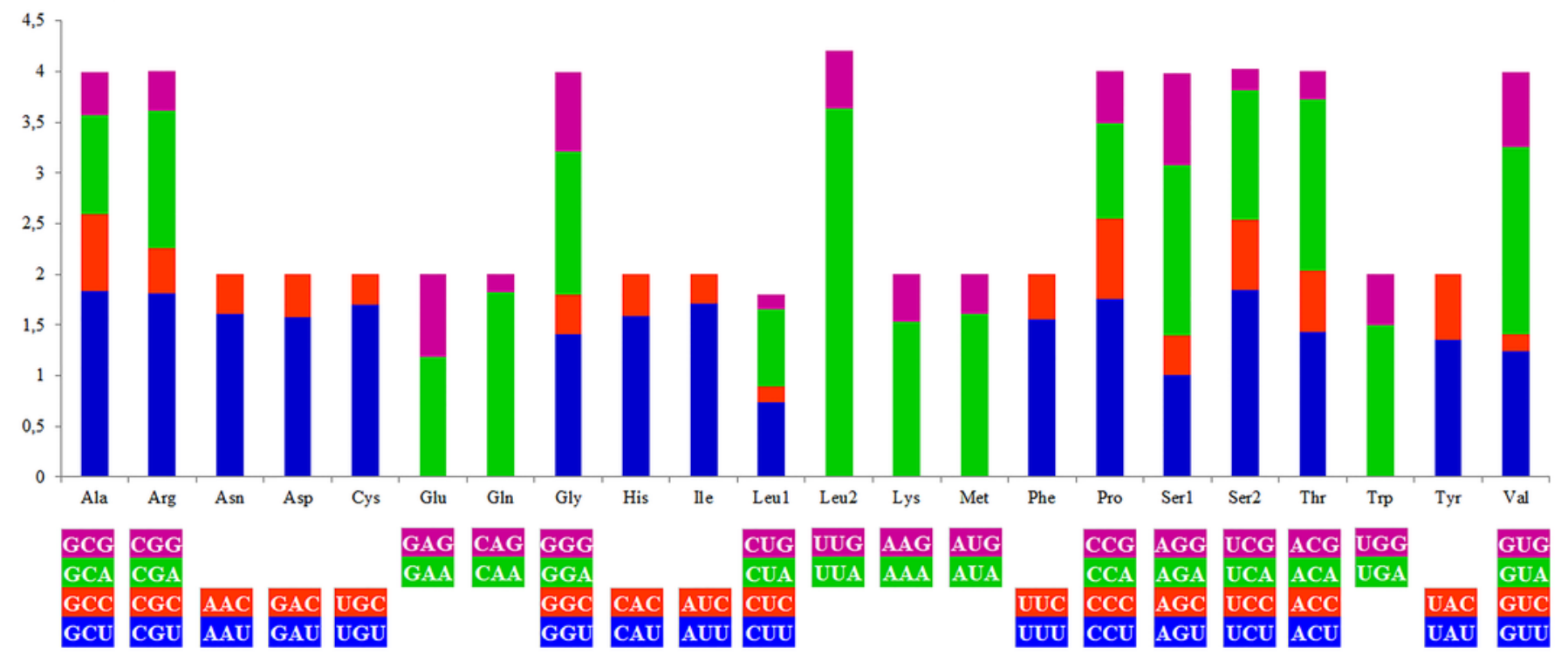


Figure 3

Predicted secondary structure of putative control region of $A$. vulgaris mitogenome.

Nucleotides are coloured as follows: Adenine is green, thymine is red, cytosine is blue and guanine is black. The poly-T stretch is labelled with purple.

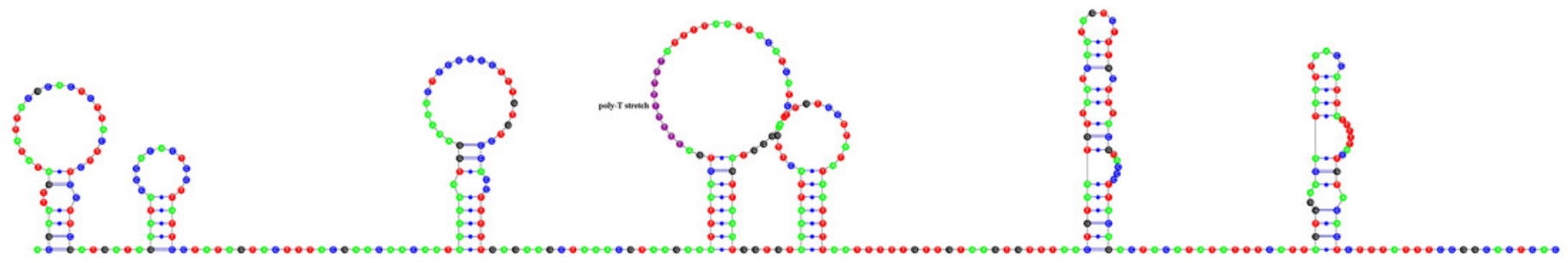


Figure 4

Stylommatophoran phylogenetic tree constructed under BI using the dataset 8P12RNA.

Carychium tridentatum (Ellobioidea), Platevindex mortoni (Systellommatophora) and Galba pervia (Hygrophila) were used as outgroup. Nodes are labelled with numbers refer to hypothetical ancestral mitogenome organizations inferred by MLGO.
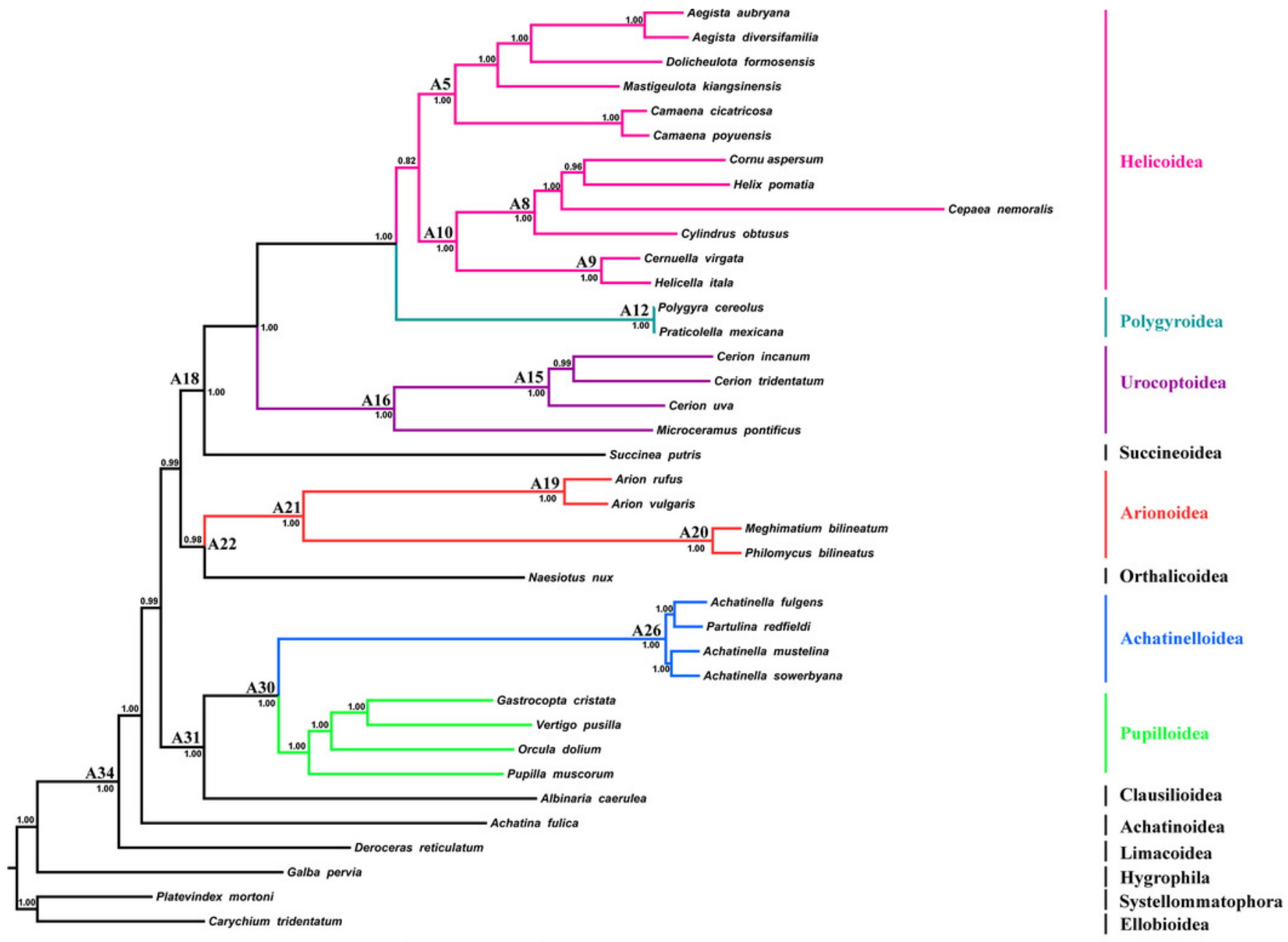
Figure 5

Dated phylogenetic tree.

The axis on the bottom refers to million years. Letters in the boxes refers to external

calibration points. The split between $A$. vulgaris and $A$. rufus was shown with a red bar, while the remainings were shown with blue bars.

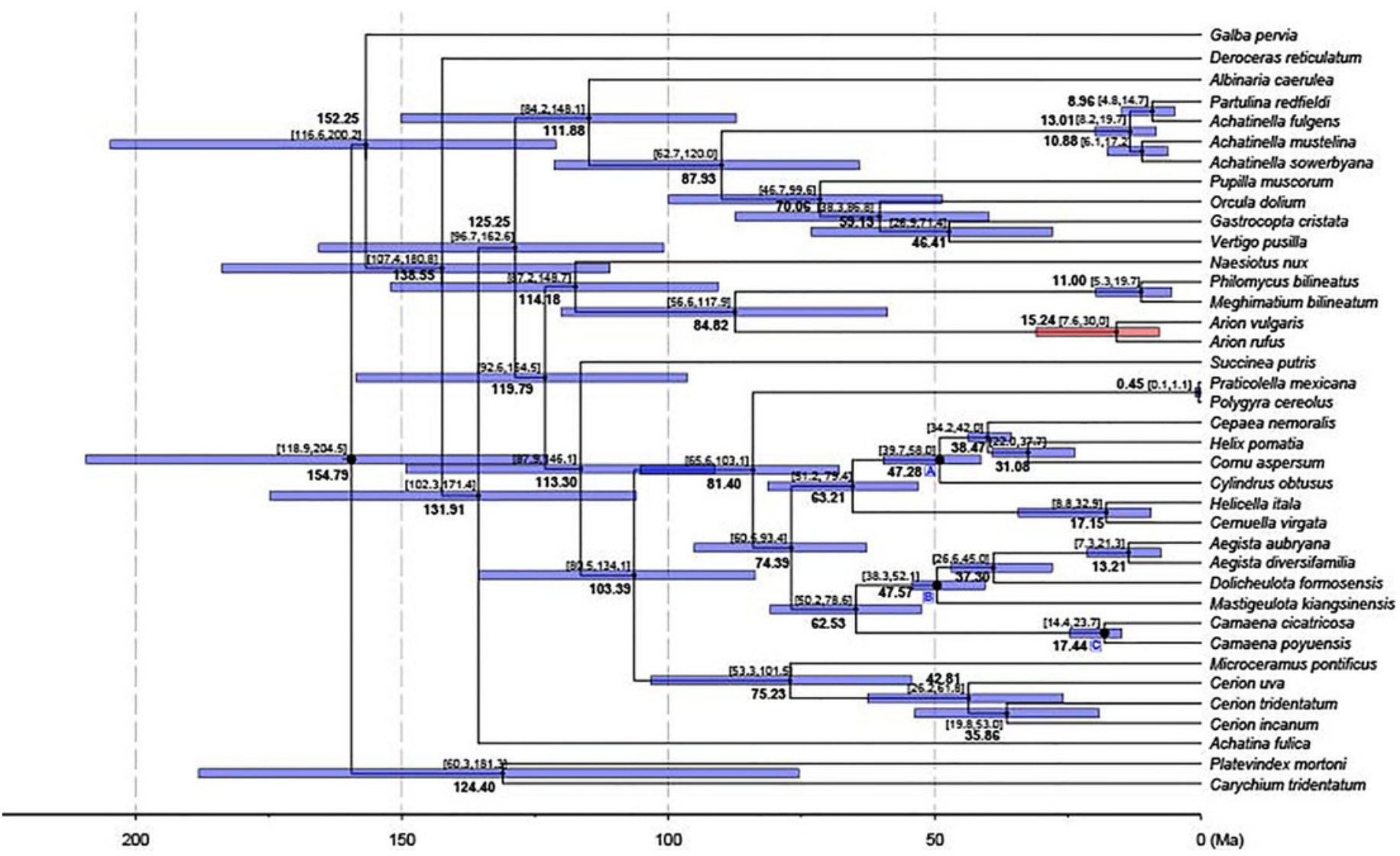




\section{Table $\mathbf{1}$ (on next page)}

List of stylommatophoran mitogenomes used in phylogenetic and comparative analyses 
1 Table 1. List of stylommatophoran mitogenomes used in phylogenetic and comparative analyses

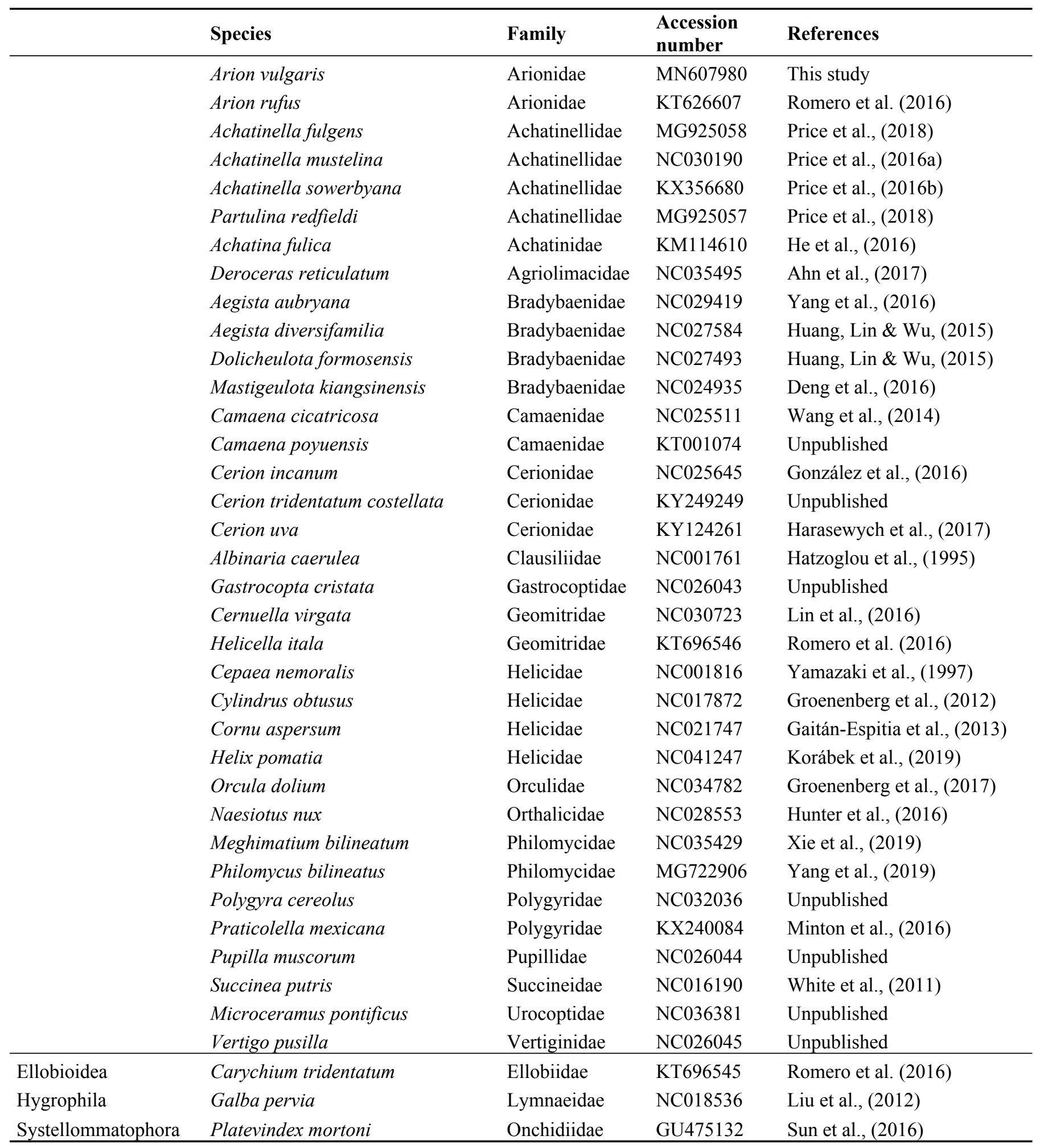


Table 2 (on next page)

Mitogenome summary of Arion vulgaris 
1 Table 2. Mitogenome summary of Arion vulgaris

\begin{tabular}{|c|c|c|c|c|c|c|c|c|}
\hline Gene & Strand & From & To & Size & Start codon & Stop codon & Anticodon & IGN \\
\hline$C O X 1$ & $\mathrm{~J}$ & 1 & 1530 & 1530 & TTG & TAG & & 4 \\
\hline$t R N A-V a l$ & $\mathrm{~J}$ & 1535 & 1600 & 66 & & & UAC & 0 \\
\hline $16 S r R N A$ & $\mathrm{~J}$ & 1601 & 2613 & 1013 & & & & 0 \\
\hline$t R N A-L e u$ & $\mathrm{~J}$ & 2614 & 2675 & 62 & & & UAG & 11 \\
\hline tRNA-Pro & $\mathrm{J}$ & 2687 & 2752 & 66 & & & UGG & 13 \\
\hline$t R N A-A l a$ & $\mathrm{~J}$ & 2766 & 2831 & 66 & & & UGC & 7 \\
\hline ND6 & $\mathrm{J}$ & 2839 & 3312 & 474 & ATG & TAG & & -41 \\
\hline ND5 & $\mathrm{J}$ & 3272 & 4960 & 1689 & $\mathrm{ACA}$ & TAA & & -10 \\
\hline$N D 1$ & $\mathrm{~J}$ & 4951 & 5853 & 903 & ATG & TAG & & 15 \\
\hline$N D 4 L$ & $\mathrm{~J}$ & 5869 & 6163 & 295 & ATA & T- & & -15 \\
\hline CYTB & $\mathrm{J}$ & 6149 & 7228 & 1080 & ATG & TAA & & -2 \\
\hline$t R N A-A s p$ & $\mathrm{~J}$ & 7227 & 7296 & 70 & & & GUC & 10 \\
\hline$t R N A-C y s$ & $\mathrm{~J}$ & 7307 & 7363 & 57 & & & GCA & 0 \\
\hline tRNA-Phe & $\mathrm{J}$ & 7364 & 7425 & 62 & & & GAA & 0 \\
\hline COX2 & $\mathrm{J}$ & 7426 & 8094 & 669 & ATG & TAG & & 1 \\
\hline$t R N A-\operatorname{Trp}$ & $\mathrm{J}$ & 8096 & 8160 & 65 & & & UCA & 91 \\
\hline$t R N A-T y r$ & $\mathrm{~J}$ & 8252 & 8315 & 67 & & & GUA & 0 \\
\hline Control region & $\mathrm{J}$ & 8316 & 8685 & 370 & & & & 0 \\
\hline$t R N A-G l y$ & $\mathrm{~J}$ & 8686 & 8763 & 78 & & & $\mathrm{UCC}$ & -20 \\
\hline$t R N A-H i s$ & $\mathrm{~J}$ & 8744 & 8809 & 66 & & & GUG & -3 \\
\hline$t R N A-G l u$ & $\mathrm{~N}$ & 8807 & 8873 & 67 & & & UUC & 5 \\
\hline$t R N A-G l n$ & $\mathrm{~N}$ & 8879 & 8942 & 64 & & & UUG & 0 \\
\hline $12 S r R N A$ & $\mathrm{~N}$ & 8943 & 9689 & 747 & & & & 0 \\
\hline$t R N A-M e t$ & $\mathrm{~N}$ & 9690 & 9754 & 65 & & & CAU & 0 \\
\hline tRNA-Leu & $\mathrm{N}$ & 9755 & 9820 & 66 & & & UAA & -32 \\
\hline ATP8 & $\mathrm{N}$ & 9789 & 9971 & 183 & GTG & TAA & & 0 \\
\hline$t R N A-A s n$ & $\mathrm{~N}$ & 9972 & 10033 & 62 & & & GUU & -8 \\
\hline ATP6 & $\mathrm{N}$ & 10026 & 10688 & 663 & ATA & TAA & & -9 \\
\hline$t R N A-A r g$ & $\mathrm{~N}$ & 10680 & 10746 & 67 & & & UCG & 3 \\
\hline ND3 & $\mathrm{N}$ & 10750 & 11094 & 345 & ATG & TAA & & 13 \\
\hline$t R N A-S e r 2$ & $\mathrm{~N}$ & 11108 & 11176 & 69 & & & UGA & 49 \\
\hline$t R N A-S e r 1$ & $\mathrm{~J}$ & 11226 & 11283 & 58 & & & GCU & 36 \\
\hline$N D 4$ & $\mathrm{~J}$ & 11320 & 12633 & 1314 & ATA & TAG & & -18 \\
\hline$t R N A-T h r$ & $\mathrm{~N}$ & 12616 & 12681 & 66 & & & UGU & 0 \\
\hline$C O X 3$ & $\mathrm{~N}$ & 12682 & 13462 & 781 & ATG & T- & & 41 \\
\hline tRNA-Ile & $\mathrm{J}$ & 13504 & 13567 & 64 & & & GAU & 1 \\
\hline ND2 & $\mathrm{J}$ & 13569 & 14486 & 918 & ATG & TAA & & 0 \\
\hline$t R N A-L y s$ & $\mathrm{~J}$ & 14487 & 6 & 67 & & & UUU & -6 \\
\hline
\end{tabular}




\section{Table 3(on next page)}

Nucleotide composition of the Arion vulgaris mitogenome 
1 Table 3. Nucleotide composition of the Arion vulgaris mitogenome

\begin{tabular}{lrrrrrrr}
\hline Feature & $\mathbf{T} \%$ & $\mathbf{C} \%$ & $\mathbf{A} \%$ & $\mathbf{G} \%$ & $\mathbf{A}+\mathbf{T} \%$ & AT-skew & GC-skew \\
\hline Whole mitogenome & 37.75 & 14.26 & 32.45 & 15.54 & 70.20 & -0.076 & 0.043 \\
Protein coding genes & 39.90 & 14.61 & 29.44 & 16.05 & 69.34 & -0.151 & 0.047 \\
First codon position & 33.54 & 14.01 & 30.64 & 21.81 & 64.18 & -0.045 & 0.218 \\
Second codon position & 45.65 & 19.42 & 18.55 & 16.38 & 64.21 & -0.422 & -0.085 \\
Third codon position & 40.50 & 10.39 & 39.14 & 9.97 & 79.64 & -0.017 & -0.021 \\
Protein coding genes-J & 39.78 & 14.34 & 29.72 & 16.16 & 69.50 & -0.145 & 0.060 \\
First codon position-J & 32.94 & 13.93 & 31.23 & 21.90 & 64.17 & -0.027 & 0.222 \\
Second codon position-J & 45.91 & 19.07 & 18.53 & 16.49 & 64.44 & -0.425 & -0.073 \\
Third codon position-J & 40.50 & 10.01 & 39.41 & 10.08 & 79.90 & -0.014 & 0.003 \\
Protein coding genes-N & 40.42 & 15.80 & 28.19 & 15.60 & 68.60 & -0.178 & -0.006 \\
First codon position-N & 36.24 & 14.37 & 27.98 & 21.41 & 64.22 & -0.129 & 0.197 \\
Second codon position-N & 44.50 & 20.95 & 18.65 & 15.90 & 63.15 & -0.409 & -0.137 \\
Third codon position-N & 40.52 & 12.08 & 37.92 & 9.48 & 78.44 & -0.033 & -0.121 \\
tRNA genes & 36.40 & 11.48 & 36.33 & 15.80 & 72.72 & -0.001 & 0.158 \\
rRNA genes & 33.24 & 13.58 & 38.18 & 15.00 & 71.42 & 0.069 & 0.050 \\
Control region & 38.92 & 18.65 & 30.81 & 11.62 & 69.73 & -0.116 & -0.232 \\
\hline
\end{tabular}




\section{Table 4(on next page)}

Likelihood ratios of PAML analysis showing different selective pressures on the mitochondrial PCGs in Stylommatophora 
1 Table 4. Likelihood ratios of PAML analysis showing different selective pressures on the mitochondrial PCGs in Stylommatophora

\begin{tabular}{|c|c|c|c|c|c|c|c|c|c|c|c|}
\hline \multicolumn{2}{|c|}{ Models $^{\mathrm{a}}$} & \multicolumn{2}{|l|}{ A } & \multicolumn{2}{|l|}{$\mathrm{B}$} & \multicolumn{2}{|l|}{$\mathrm{C}$} & \multicolumn{2}{|l|}{ A-B } & \multicolumn{2}{|l|}{$\mathrm{B}-\mathrm{C}$} \\
\hline Gene & $\omega$ & $\ln \mathrm{L}^{\mathrm{b}}$ & $\mathrm{Np}^{\mathrm{c}}$ & $\ln \mathrm{L}$ & $\mathrm{Np}$ & $\ln \mathrm{L}$ & $\mathrm{Np}$ & LRT & $\mathrm{P}$ & LRT & $\mathrm{P}^{\mathrm{d}}$ \\
\hline ATP6 & 0.0509 & -19658.6890 & & -19377.7446 & & -19374.7961 & & 561.8887 & 0.000 & -5.896982 & 0.015 \\
\hline ATP8 & 0.2198 & -6460.1406 & & -6355.5745 & & -6355.5745 & & 209.1322 & 0.000 & -0.000006 & 1.000 \\
\hline$C O X 1$ & 0.0129 & -26428.6827 & & -26169.9332 & & -26169.9332 & & 517.4990 & 0.000 & 0.000000 & 1.000 \\
\hline$C O X 2$ & 0.0393 & -16022.1910 & & -15851.6973 & & -15848.6152 & & 340.9874 & 0.000 & -6.164250 & 0.013 \\
\hline$C O X 3$ & 0.0317 & -18617.4781 & & -18345.8456 & & -18341.7284 & & 543.2650 & 0.000 & -8.234404 & 0.004 \\
\hline СYTB & 0.0416 & -26893.7004 & & -26297.6496 & & -26297.6496 & & 1192.1017 & 0.000 & 0.000082 & 0.992 \\
\hline ND1 & 0.0430 & -24857.6972 & 76 & -24528.7292 & 78 & -24529.0150 & 79 & 657.9359 & 0.000 & 0.571480 & 0.450 \\
\hline ND2 & 0.0670 & -31769.5279 & & -31502.5684 & & -31498.5036 & & 533.9191 & 0.000 & -8.129668 & 0.004 \\
\hline ND3 & 0.0607 & -11403.3678 & & -11183.4729 & & -11183.4729 & & 439.7899 & 0.000 & 0.000010 & 1.000 \\
\hline ND4 & 0.0511 & -40498.0727 & & -40032.1913 & & -40026.0861 & & 931.7628 & 0.000 & -12.210500 & 0.000 \\
\hline$N D 4 L$ & 0.0727 & -10118.1495 & & -10076.4001 & & -10075.2708 & & 83.4989 & 0.000 & -2.258408 & 0.133 \\
\hline ND5 & 0.0676 & -51970.2413 & & -51088.0681 & & -51092.3346 & & 1764.3464 & 0.000 & 8.533012 & 0.003 \\
\hline ND6 & 0.1009 & -16916.1956 & & -16691.7006 & & -16691.7006 & & 448.9899 & 0.000 & 0.000018 & 1.000 \\
\hline
\end{tabular}

2 Degrees of freedom $=1$.

3 a A: All branches have one $\omega$; B: All branches have same $\omega=1$; C: Each branch has its own $\omega$.

$4 \quad \mathrm{~b}$ The natural algorithm of the likelihood value.

$5{ }^{\mathrm{c}}$ Number of parameters.

$6 \quad{ }^{\mathrm{d}}$ Bold faced figure indicate the statistical significance $(\mathrm{P}<0.05)$. 


\section{Table 5 (on next page)}

Genes and branches detected to be exposed episodic diversifying selection using the aBSREL approach. 
1 Table 5. Genes and branches detected to be exposed episodic diversifying selection using the 2 aBSREL approach.

\begin{tabular}{lclcr}
\hline Gene & $\begin{array}{c}\text { Number of Selected } \\
\text { Branches (P<0.05) }\end{array}$ & Taxon & $\boldsymbol{\omega}$ & $\begin{array}{r}\text { Proportion of Codons } \\
\text { Under Selection }\end{array}$ \\
\hline ATP8 & 1 & Microceramus pontificus & 288 & 0.460 \\
COX1 & 1 & Achatinella mustelina & 2180 & 0.086 \\
COX3 & 2 & Arionoidea & 670 & 0.053 \\
& 1 & Philomycus bilineatus & 119 & 0.092 \\
ND3 & 1 & Helicella itala & 49.4 & 0.220 \\
ND4 & 1 & Succinea putris & 4.18 & 0.370 \\
ND6 & & Vertigo pusilla & 15.6 & 0.370 \\
\hline
\end{tabular}

3 
Table 6(on next page)

Genes/codons under diversifying or positive selection under codon-based models. 
1 Table 6. Genes/codons under diversifying or positive selection under codon-based models.

\begin{tabular}{|c|c|c|c|}
\hline Gene & BEB & FUBAR & MEME \\
\hline ATP6 & - & 4 & 44 \\
\hline ATP8 & - & 44 & $44,57,64,92,109$ \\
\hline$C O X 1$ & - & - & - \\
\hline COX2 & - & 32 & - \\
\hline$C O X 3$ & - & - & - \\
\hline$C Y T B$ & - & 12 & 12 \\
\hline$N D 1$ & - & - & - \\
\hline ND2 & 188 & - & $14,16,174$ \\
\hline ND3 & - & - & 27 \\
\hline ND4 & $109,170,192,301,386,427$ & - & 9,99 \\
\hline$N D 4 L$ & 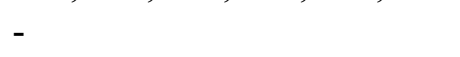 & 13,57 & $13,57,109,111$ \\
\hline ND5 & 451 & - & 260,501 \\
\hline ND6 & - & - & $109,179,183$ \\
\hline
\end{tabular}

2 